Preprint version, Reference: Pulatsu, Bora, Ece Erdogmus, Paulo B Lourenço, Jose V Lemos, and Kagan Tuncay. 2020. "Simulation of the In-Plane Structural Behavior of Unreinforced Masonry Walls and Buildings Using DEM." Structures 27 (June). Elsevier: 2274-2287. doi:10.1016/j.istruc.2020.08.026.

\title{
Simulation of the In-Plane Structural Behavior of Unreinforced Masonry Walls and Buildings using DEM
}

3 Bora Pulatsu ${ }^{\mathrm{a} *}$, Ece Erdogmus ${ }^{\mathrm{b}}$, Paulo B. Lourenço ${ }^{\mathrm{a}}$, Jose V. Lemos ${ }^{\mathrm{c}}$ and Kagan Tuncay ${ }^{\mathrm{d}}$

4 Abstract: In this study, a novel computational modeling strategy is proposed to estimate the lateral

5 load capacity and behavior of unreinforced masonry (URM) structures. All commonly noted

6 failure mechanisms are captured via the proposed modeling strategy using the discrete element

7 method (DEM) in three-dimensions (3D). Masonry walls are represented as a system of elastic

8 discrete blocks, where the nodal velocities are evaluated by integrating the equations of motion

9 using the central difference method. Then, the mechanical interactions among adjacent blocks are

10 examined utilizing the relative contact displacements and employed in the contact stress

11 calculation. Through this research, a new stress-displacement contact constitutive model is

12 considered and implemented in the commercial software 3DEC, which includes softening stress-

13 displacement behavior for tension, shear, and compression along with the fracture energy concept.

14 The results of the discontinuum models are validated on small- and large-scale experimental

15 studies available in the literature with good agreement. Furthermore, important inferences are

16 made regarding the effect of block size, the number of contact points, and contact stiffness values

17 for robust and accurate simulations of masonry walls.

18 Keywords: computational modeling; contact mechanics; discrete element method; masonry;

19 unreinforced masonry.

Bora Pulatsu University of Nebraska-Lincoln, United States bpulatsu@ unomaha.edu

Ece Erdogmus University of Nebraska-Lincoln, United States

Paulo B. Lourenço University of Minho, ISISE, Portugal

José V. Lemos LNEC, Portugal

Kagan Tuncay Middle East Technical University, Turkey 
Preprint version, Reference: Pulatsu, Bora, Ece Erdogmus, Paulo B Lourenço, Jose V Lemos, and Kagan Tuncay. 2020. "Simulation of the In-Plane Structural Behavior of Unreinforced Masonry Walls and Buildings Using DEM." Structures 27 (June). Elsevier: 2274-2287. doi:10.1016/j.istruc.2020.08.026.

\section{Introduction}

Unreinforced masonry (URM) structures constitute the vast majority of architectural heritage and existing buildings in many countries, which are typically vulnerable during seismic events.

4 Therefore, a better understanding of their seismic behavior is critically important in order to provide appropriate structural interventions and to preserve their integrity [1]. However, it is worth noting that the behavior of masonry structures is a complex problem due to the highly non-linear and composite nature of the material, consisting of units (e.g., clay bricks, stones, concrete or earth blocks) and lime- or cement-based mortar. Furthermore, the difference in the properties of unit and mortar, dimensions of masonry units, mortar thickness, and quality of the workmanship are some of the factors that influence the capacity and mechanics of masonry structures. In general, mortar joints and the unit-mortar interfaces are the weak planes for masonry walls, which yield crack localization through the bed and head joints. Furthermore, joint dislocations, cracking- and compression-failure of masonry units are the other defects that can be observed in URM walls subjected to lateral forces. This study aims to provide a tool for a deeper understanding of URM structures subjected to in-plane lateral loading, considering the effect of material nonlinearity, localization of cracks, and workmanship via advanced numerical methods.

Computational modeling strategies used to assess the response of masonry structures in the literature can be categorized as continuum and discontinuum models. In continuum-based models (also referred to as macro-modeling), based on the Finite Element Method, masonry is represented as a fictitious homogeneous anisotropic continuous medium that can be replicated using plasticity or other macro-scale constitutive relationships. Note that, in this case, there is no distinction made

22 between the units and mortar; hence, the internal structure of masonry cannot be described explicitly, and the damage within the structure is smeared out through a continuous medium. The material parameters for macro-models can be obtained experimentally, performed on large size specimens under relatively homogenous stress states. As macro-modeling is computationally quite affordable and requires fewer number of parameters, it is applicable for practice-oriented analyses of the large scale structures [2]. Applications of macro-models on various URM structures can be found in [3-10]. Still, the aforementioned limitations of macro-modeling can be overcome by

29 discontinuum type of analysis that is referred to as micro-modeling [11], where the masonry units, 30 mortar, and unit-mortar interfaces are represented explicitly to allow crack localization, joint 
Preprint version, Reference: Pulatsu, Bora, Ece Erdogmus, Paulo B Lourenço, Jose V Lemos, and Kagan Tuncay. 2020. "Simulation of the In-Plane Structural Behavior of Unreinforced Masonry Walls and Buildings Using DEM." Structures 27 (June). Elsevier: 2274-2287. doi:10.1016/j.istruc.2020.08.026.

opening, and frictional sliding failures. Although micro-models yield an accurate representation of the material, it is not practical to analyze large structures since input parameters are required for each constituent of masonry, and they demand larger computational resources [12]. In this research, a simplified approach based on the discrete element method (DEM) is employed, called simplified micro-modeling, to compromise between the required level of accuracy and computational cost. In simplified micro-models, masonry units are expanded up to the halfthickness of the mortar joints, so that the units are simulated as rectangular continuum blocks, whereas the influence of mortar joints is represented via zero-thickness interfaces, as shown in Figure 1.

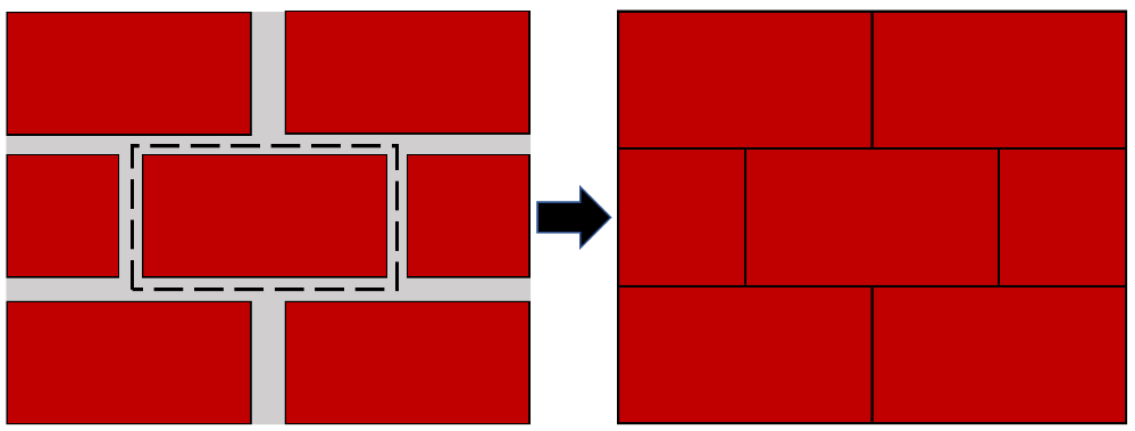

Figure 1. Left: Illustration of masonry (unit-mortar assembly), Right: Representation of the simplified micro-models with zero-thickness interfaces.

In FEM, the discontinuum representation of masonry is accomplished using interface elements

15 for the joints. DEM formulates the same problem as a system of discrete blocks (or bodies), 16 mechanically interacting with each other along their boundaries [13]. Thus, the structural behavior 17 of a discrete element model is directly related to the contact constitutive law among the 18 neighboring blocks that can be rigid or deformable. Rigid blocks may be preferable for dynamic 19 analysis compared to deformable blocks since the rigid block model has less computational 20 demand [14]. In DEM, discrete bodies can be represented as circular particles or polyhedral blocks 21 considering different scales, which depend on the type of problem [15-19].

22 During the last several decades, discrete element modeling became an attractive solution in 23 the analyses of different types of masonry structures due to its capability of capturing the non24 linear behavior and collapse mechanisms of masonry systems [20-23]. It should be noted that a 
Preprint version, Reference: Pulatsu, Bora, Ece Erdogmus, Paulo B Lourenço, Jose V Lemos, and Kagan Tuncay. 2020. "Simulation of the In-Plane Structural Behavior of Unreinforced Masonry Walls and Buildings Using DEM." Structures 27 (June). Elsevier: 2274-2287. doi:10.1016/j.istruc.2020.08.026.

1 family of similar numerical techniques is available in the literature within the framework of DEM, such as non-smooth contact dynamics method (NSCD), discontinuous deformation analysis (DDA), and combined finite-discrete element method (FDEM, FEM/DEM). The mentioned DEMbased computational techniques differentiate based on the contact type (soft or hard contact), contact behavior, and/or implementation of the numerical procedures (explicit or implicit). For instance, the NSCD method utilizes an impenetrable contact model (Signorini's impenetrability condition) with an implicit time integration solver. The successful applications of the NSCD method and its detailed explanation is given in the relevant studies in the literature, where the seismic vulnerability and performance of masonry structures (e.g., towers, walls, and churches) are assessed using rigid blocks [24-27]. Different from the NSCD method, explicit solution

11 procedure and a soft-contact approach are used in this research within the framework of DEM, where the penetration of the adjacent blocks is allowed relying on the contact stiffnesses defined

13 at each contact points. Another similar modeling strategy, presented by Munjiza [28], combines

14 the features of discrete and finite element methods (FDEM) to simulate the fracture and 15 fragmentation processes of deformable bodies via contact elements, implemented within the finite 16 element mesh [29-31]. Further discussions about the applications and comparison of DEM and 17 FEM based modeling approaches, the readers are referred to available studies in the literature [3218 35].

The present research provides novel contributions in discrete element modeling of masonry structures as well as in the analysis of URM walls. The specific goals of this research can be 21 summarized as follows:

- To provide a robust discontinuum based approach in the lateral analysis of URM walls and large-scale URM structures by incorporating fracture energy-based contact constitutive models in DEM, accounting for the intrinsic softening behavior of the material.

- To investigate the effect of micro-mechanical properties on the macro behavior of the computational models.

- To shed light on the progressive damage mechanism in URM walls and structures from the early stage of cracking to the eventual collapse using the proposed modeling strategy.

30 masonry assemblages with or without mortar joints as well as in any geometrical form. In the 
Preprint version, Reference: Pulatsu, Bora, Ece Erdogmus, Paulo B Lourenço, Jose V Lemos, and Kagan Tuncay. 2020. "Simulation of the In-Plane Structural Behavior of Unreinforced Masonry Walls and Buildings Using DEM." Structures 27 (June). Elsevier: 2274-2287. doi:10.1016/j.istruc.2020.08.026.

1 following sections, the computational background of DEM, the validation of the proposed 2 modeling strategy on small and large scale URM structures, and the sensitivity analyses are 3 presented.

\section{$5 \quad 2$ Computational Framework}

This research adopts a discrete element formulation of URM brickwork masonry walls, where masonry is represented as distinct brick-shaped blocks based on DEM, originally developed by Cundall [36]. Numerical models are developed using a commercial software called 3DEC, developed by Itasca [37]. The computational procedure of DEM relies on the integration of the equation of motion, which is solved for each block in the system. In the present study, masonry units are represented as linear elastic (deformable) blocks that are discretized into constant strain

12 tetrahedral elements (denoted as finite-difference zones). The mechanical interaction between the

13 adjacent blocks is analyzed at each point defined along the contact surfaces, as shown in Figure 2.

14 Contact stresses are calculated in the normal $(\sigma)$ and shear $(\tau)$ directions based on the assigned 15 contact stiffness to each spring (see Figure 2) $k_{n}$ and $k_{s}$, respectively. Inelastic properties are also 16 defined for the spring in the normal and shear direction, namely tensile strength $f_{t}$, cohesion $c$ and 17 friction angle $\phi$.



19 Figure 2. Representation of masonry units (referred to as deformable blocks) discretized into 
Preprint version, Reference: Pulatsu, Bora, Ece Erdogmus, Paulo B Lourenço, Jose V Lemos, and Kagan Tuncay. 2020. "Simulation of the In-Plane Structural Behavior of Unreinforced Masonry Walls and Buildings Using DEM." Structures 27 (June). Elsevier: 2274-2287. doi:10.1016/j.istruc.2020.08.026.

The governing set of differential equations is numerically solved using the central difference integration scheme to calculate the nodal velocities for each block in the system. Quasistatic solutions are obtained via a dynamic relaxation algorithm that utilizes artificial damping.

4 The equation of motion is given in Equation 1, where the nodal velocities are evaluated at the mid5 intervals of the time step $(\Delta t)$.

$$
\begin{gathered}
\dot{u}_{i}^{t+\Delta t / 2}=\dot{u}_{i}^{t-\Delta t / 2}+\left[\Sigma F_{i}-\left(F_{d}\right)_{i}\right]^{\Delta t} / m_{n} \\
\left(F_{d}\right)_{i}=\gamma\left|\Sigma F_{i}\right| \operatorname{sgn}\left(\dot{u}_{i}^{t-\Delta t / 2}\right)
\end{gathered}
$$

Here, $\dot{u}, F$, and $m_{n}$ are the velocity vector, nodal force vector, and lumped nodal mass, respectively, calculated for each node (or so called gridpoint). Nodal masses can be represented as a diagonal mass matrix, where each gridpoint shares $1 / 4$ of the total mass for a tetrahedral element.

11 The force vector $F$ consists of external loads, contact forces (only for gridpoint along the surface

12 of the block), gravity forces and the contribution of the internal stress in the zones adjacent to the 13 gridpoint (internal nodal forces, $F_{k}^{i n t}$ ) that can be obtained as

$$
F_{k}^{i n t}=\int_{S} \sigma_{k j} n_{j} d s
$$

where $n_{j}$ is the outward normal to the surface $S$ (closed polyhedral surface, defined by the centroid of each zone connected to vertex) and $\sigma_{k j}$ indicates the zone stress tensor (i.e., within each constant strain tetrahedral element). In the given expression, a local form of damping is applied by defining the force $\left(F_{d}\right)$ with a damping constant, $\gamma$ (default value is 0.8 ), which remains unchanged during the analysis. The damping force is calculated proportionally to the magnitude of the unbalanced force that opposes the motion related to the velocity vector $(\operatorname{sgn}(\xi)=1$, if $\xi \geqslant$ $0 ; \operatorname{sgn}(\xi)=-1$, if $\xi<0$ ) [38]. Further explanations of the implemented local damping algorithm 
Preprint version, Reference: Pulatsu, Bora, Ece Erdogmus, Paulo B Lourenço, Jose V Lemos, and Kagan Tuncay. 2020. "Simulation of the In-Plane Structural Behavior of Unreinforced Masonry Walls and Buildings Using DEM." Structures 27 (June). Elsevier: 2274-2287. doi:10.1016/j.istruc.2020.08.026.

can be found in [39]. The obtained nodal velocities are then utilized to update block positions and to calculate the relative contact displacements. Through the dynamic solution scheme of DEM, contact conditions are tracked by a contact detection algorithm based on the common plane concept, explained in [40]. Note that the contact detection algorithm provides a unit normal vector (defined on a plane) and updates its direction as long as the adjacent blocks (hence the contact planes) continue to move. This means that the normal vector of the contact plane is utilized in the computation of the relative normal displacements among the contact points. The same analogy is also applicable for shear direction, which is perpendicular to the normal vector. During the analysis, numerical stability is attempted to be ensured providing a sufficiently small-time step (less than the critical time step, $\Delta t_{c r}$ ) to capture the internal block deformation and inter-block displacements, which is given by Equation 3.

$$
\Delta t_{c r}=2 \sqrt{m_{n} / k_{g p}}
$$

Here, $k_{g p}$ denotes the nodal stiffness obtained by adding zone and contact (only the gridpoint on the faces) stiffness [41]. Once the normal and shear contact increments $\left(\Delta u_{n}, \Delta u_{s}\right)$ are obtained based on the relative displacements at the contact points, the corresponding normal $(\Delta \sigma)$ and shear $(\Delta \tau)$ stress increments are computed (Equation 4). Next, the contact stress increments are added to the old ones $\left(\sigma^{\text {old }}, \tau^{\text {old }}\right)$ to calculate the new stresses $\left(\sigma^{\text {new }}, \tau^{\text {new }}\right)$ that are updated and corrected (if applicable) according to the proposed contact constitutive law. Finally, the new contact stresses, related to each gridpoint at the surface of the block, are multiplied with the specified contact area (equal to the summation of $1 / 3$ of each surrounding triangles around the node) and then employed in the equations of motion.

In this study, instead of using the standard built-in contact model in 3DEC, a new contactconstitutive model is implemented to be utilized in the explicit solution scheme of DEM (Figure $3)$. It is worth noting that the proposed contact stress-displacement behavior captures all possible

26 failure modes in masonry given in $[15,16]$, including softening regimes in tension and shear by considering fracture energy concept at the contact stress-displacement functions. The Coulomb- 
Preprint version, Reference: Pulatsu, Bora, Ece Erdogmus, Paulo B Lourenço, Jose V Lemos, and Kagan Tuncay. 2020. "Simulation of the In-Plane Structural Behavior of Unreinforced Masonry Walls and Buildings Using DEM." Structures 27 (June). Elsevier: 2274-2287. doi:10.1016/j.istruc.2020.08.026.

1 slip joint model is employed in the shear direction, which requires cohesion $\left(c_{0}\right)$ and friction angle $2\left(\phi_{0}\right)$ parameters as well as the residual cohesion $\left(c_{r e s}\right)$ and frictional angles $\left(\phi_{\text {res }}\right)$. Furthermore, 3 nonlinear behavior is considered in compression assuming a simple linear softening function, 4 accounting for compressive fracture energy.

$$
\begin{gathered}
\Delta \sigma=k_{n} \Delta u_{n} ; \Delta \tau=k_{s} \Delta u_{s} \\
\sigma^{\text {new }}=\sigma^{\text {old }}+\Delta \sigma ; \tau^{\text {new }}=\tau^{\text {old }}+\Delta \tau
\end{gathered}
$$
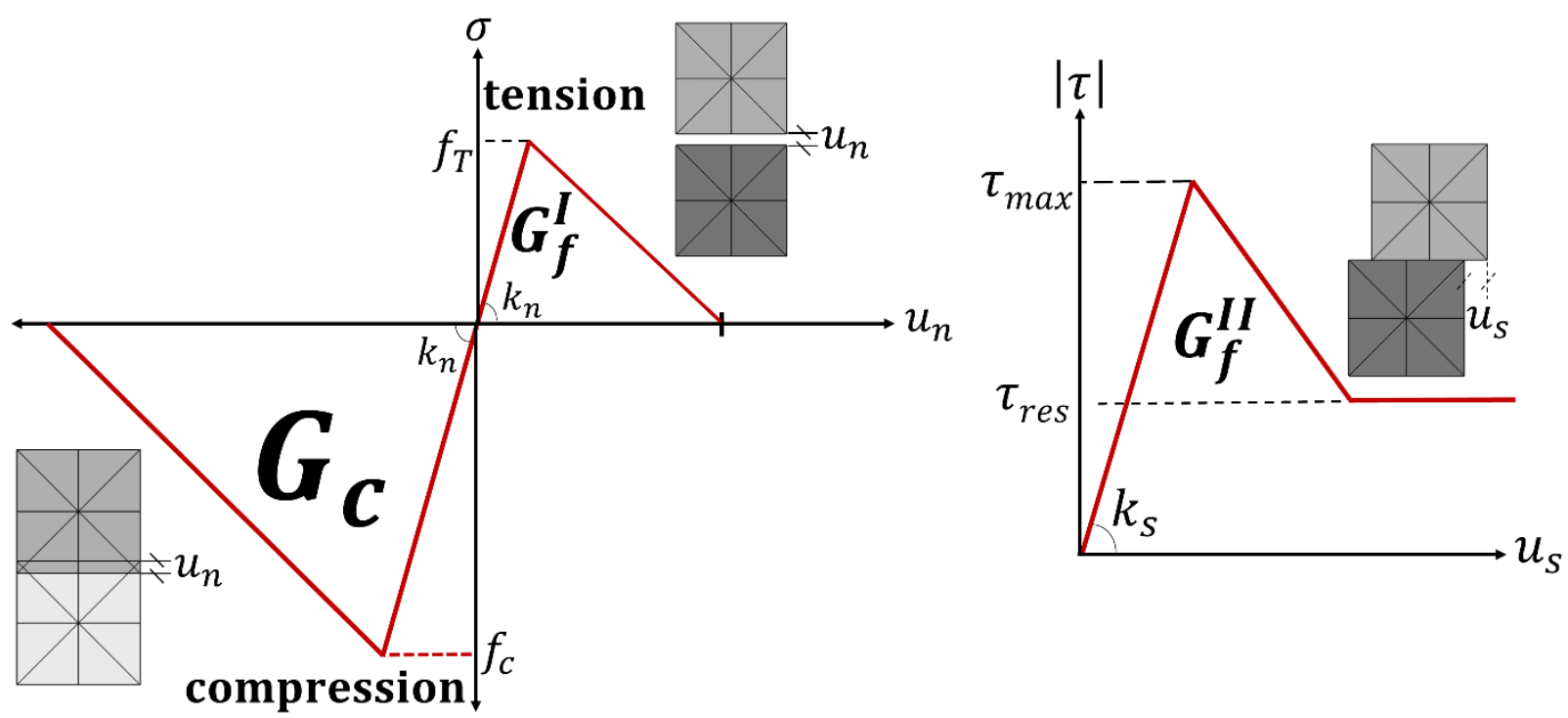

Figure 3. Contact models in the normal (left) and shear (right) directions.

The adopted contact models are written in $\mathrm{C}++$ and compiled as DLL (dynamic link library) into 3DEC via the user-defined constitutive model option, and the discussed dynamic 11 solution procedure is executed through the pseudo-time domain to analyze the collective 12 mechanics of discrete blocks. In the next section, validation of the proposed modeling strategy is 13 presented using the most usual test results for masonry: in-plane loaded masonry shear walls. 
Preprint version, Reference: Pulatsu, Bora, Ece Erdogmus, Paulo B Lourenço, Jose V Lemos, and Kagan Tuncay. 2020. "Simulation of the In-Plane Structural Behavior of Unreinforced Masonry Walls and Buildings Using DEM." Structures 27 (June). Elsevier: 2274-2287. doi:10.1016/j.istruc.2020.08.026.

\section{Validation: Shear Walls}

In this section, the proposed discontinuum modeling strategy is validated by comparing it with the results of URM shear wall experiments, available in the literature $[42,43]$, to benchmark the modeling approach. Two masonry wall types are taken into consideration: a wall with an opening at the center (referred to as hollow wall) and a complete wall with no opening (referred to as solid wall). The walls were built with 18 masonry courses using single layer solid clay bricks $\left(204 \times 98 \times 50 \mathrm{~mm}^{3}\right)$ with $10 \mathrm{~mm}$ thick mortar $(1: 2: 9$, cement:lime:sand by volume), where two courses were clamped in steel beams. Therefore, 16 courses of the shear walls are modeled as an active brickwork masonry, depicted in Figure 4. Tests were performed in two steps; first, the uniform vertical loads were applied, then the walls were subjected to increasing lateral forces. Note

11 that during the second stage of the experiment, only the upper edge of the specimen was allowed to move horizontally while vertical displacements were prevented, as shown in Figure 4.
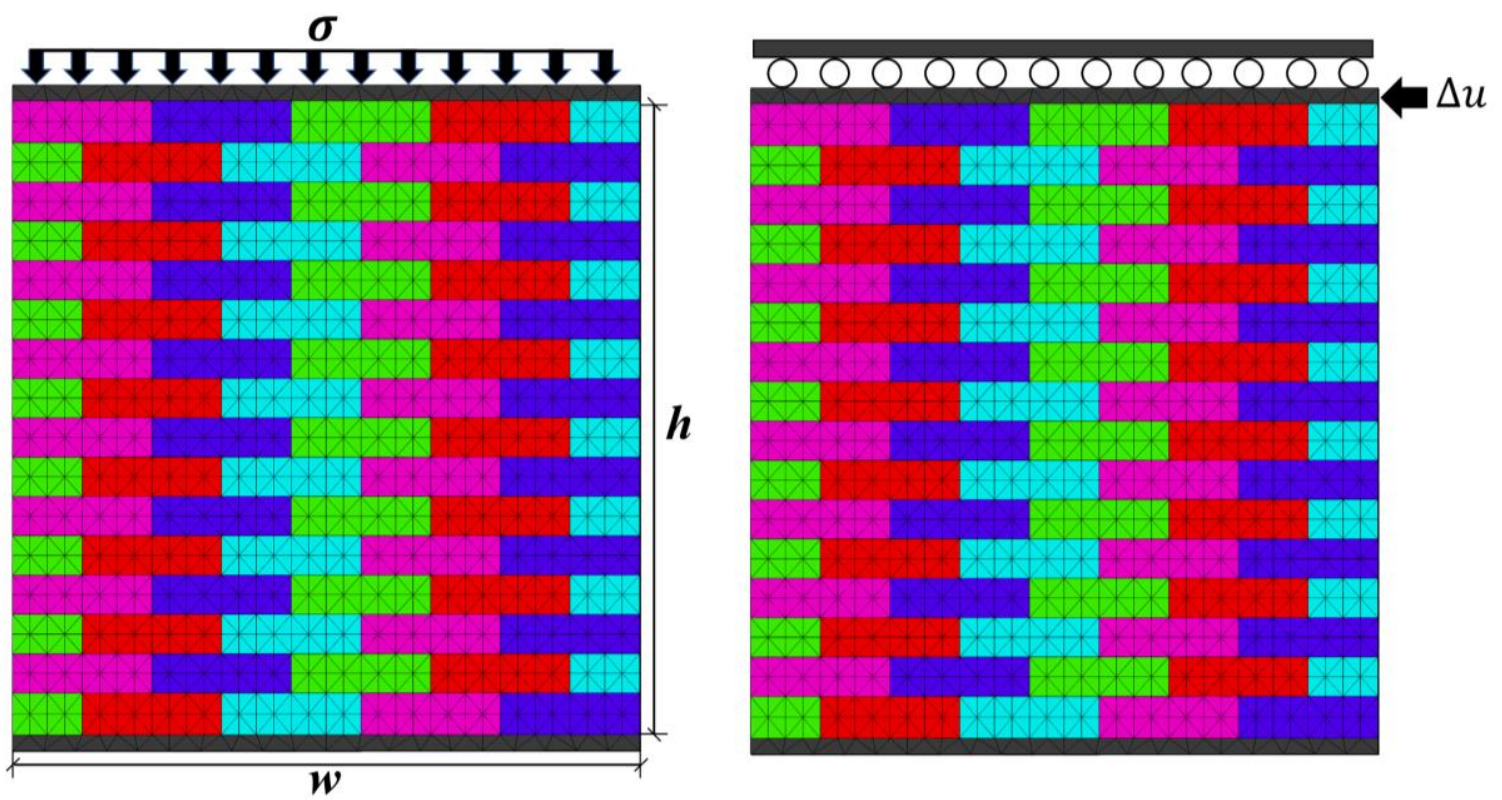

Figure 4. Illustration of the analyzed URM solid walls $(h=1 m, w=0.99 m)$ : Initial vertical

Different vertical pressures were considered in the experiment $(0.30,1.21$, and $2.21 \mathrm{MPa})$,

18 and two tests were performed for the lowest pre-compression level, shown as an envelope in Figure

19 5. Firstly, solid walls are analyzed via the simplified micro-modeling approach using the proposed 
Preprint version, Reference: Pulatsu, Bora, Ece Erdogmus, Paulo B Lourenço, Jose V Lemos, and Kagan Tuncay. 2020. "Simulation of the In-Plane Structural Behavior of Unreinforced Masonry Walls and Buildings Using DEM." Structures 27 (June). Elsevier: 2274-2287. doi:10.1016/j.istruc.2020.08.026.

1 softening contact models in tension, shear, and compression regimes. Each masonry unit is modeled as an elastic distinct block with a joint defined at the mid-section to consider a potential cracking failure within the clay bricks. The applied representation of clay bricks may be considered as the simplest solution to simulate the cracking phenomenon in masonry units; however, to simulate more complex and heterogenous fracture patterns, randomly generated irregular polyhedral blocks can be utilized as shown in $[16,44]$. Therefore, half-bricks are discretized into 80 constant-strain finite-difference volumes. Material properties are directly taken from the experimental study, whereas the contact stiffness is calculated based on the elastic modulus of each constituent of masonry and the mortar thickness $\left(t_{m}\right)$, similar to other studies $[11,45,46]$, as follows,

$$
k_{n}=\frac{E_{b} E_{m}}{t_{m}\left(E_{b}-E_{m}\right)} ; k_{s}=\frac{G_{b} G_{m}}{t_{m}\left(G_{b}-G_{m}\right)}
$$

where, $E_{b}, G_{b}, E_{m}$ and $G_{m}$ are the brick elastic modulus, brick shear modulus, mortar elastic

14 modulus, and mortar shear modulus, respectively. The input parameters, including linear and non-

15 linear contact properties, are given in Table 1. Moreover, the stiffness of the masonry units is defined as 16.7 MPa. The loading procedure in the discrete element model is established as similar

17 to the benchmark study by considering an initial vertical pressure (pre-compression, $\sigma$ ) and the

18 horizontal deflection is exerted on the top beam. Specifically, the discontinuum model is brought 19 into the quasi-static equilibrium (when the unbalanced force in the system is less than $1 \mathrm{E}-5 \mathrm{~N}$ ).

20 Then, the constant nodal velocities are prescribed for all the gridpoints located at the top of the 21 upper beam. To eliminate the numerical oscillations during the explicit solution scheme of DEM, 22 relatively low displacement rates (i.e., $1 \mathrm{~mm} / \mathrm{s}$ ) are defined at the gridpoints, which allows to obtain 23 a smooth response from the numerical models. Note that during the analysis, the reaction forces 24 are extracted and recorded from gridpoints, where the constant velocity boundary condition is 25 applied via the implemented subroutine in the software based on FISH functions (an executable 26 programming language in 3DEC). 
Preprint version, Reference: Pulatsu, Bora, Ece Erdogmus, Paulo B Lourenço, Jose V Lemos, and Kagan Tuncay. 2020. "Simulation of the In-Plane Structural Behavior of Unreinforced Masonry Walls and Buildings Using DEM." Structures 27 (June). Elsevier: 2274-2287. doi:10.1016/j.istruc.2020.08.026.

The results of the analyses demonstrate that the proposed computational models predict the strength and stress-displacement behavior of the masonry walls within an acceptable accuracy, as presented in Figure 5. Figure 6 illustrates a typical failure mechanism of a URM masonry wall under low vertical pressure (0.30 MPa), as determined from the proposed discontinuum model.

5 The obtained cracking pattern is in good agreement with the experimental findings, where the first cracks are recorded as bending cracks at the uppermost and lower bed joints developing through the opposite corners. Then, the successive cracks spread diagonally at the header joints, and shear

8 failures are observed along the bed joints. Finally, the collapse mechanism of the wall is obtained with a full diagonal crack. In the case of higher vertical pressures, cracking in masonry units become more pronounced, and higher lateral capacities are achieved, as expected.

Table 1. Contact properties - Masonry walls with solid masonry units (Subscript $u$ and $j$ refer to the units and joint (unit-mortar interface), respectively)

\begin{tabular}{|c|c|c|c|c|}
\hline \multicolumn{5}{|c|}{ Interaction within the masonry units (bricks) } \\
\hline$\left(k_{n}\right)_{u}(G P a / m)$ & $\left(k_{s}\right)_{u}(G P a / m)$ & $f_{t}(M P a)$ & $c(M P a)$ & $\phi_{0}\left(^{\circ}\right)$ \\
\hline 1000 & 1000 & 2 & 3 & 35 \\
\hline$\theta_{\text {res }}\left(^{\circ}\right)$ & $f_{c}(M P a)$ & $G_{f}^{I}(N / m)$ & $G_{f}^{I I}(N / m)$ & $G_{c}(N / m)$ \\
\hline 35 & 12 & 80 & 550 & 19000 \\
\hline \multicolumn{5}{|c|}{ Interaction between the masonry units (unit-mortar interface) } \\
\hline$\left(k_{n}\right)_{j}(G P a / m)$ & $\left(k_{s}\right)_{j}(G P a / m)$ & $f_{t}(M P a)$ & $c(M P a)$ & $\phi_{0}\left(^{\circ}\right)$ \\
\hline 82 & 36 & 0.2 & 0.3 & 35 \\
\hline$\theta_{\text {res }}\left(^{\circ}\right)$ & $f_{c}(M P a)$ & $G_{f}^{I}(N / m)$ & $G_{f}^{I I}(N / m)$ & $G_{c}(N / m)$ \\
\hline 35 & 5 & 15 & 125 & 8000 \\
\hline
\end{tabular}


Preprint version, Reference: Pulatsu, Bora, Ece Erdogmus, Paulo B Lourenço, Jose V Lemos, and Kagan Tuncay. 2020. "Simulation of the In-Plane Structural Behavior of Unreinforced Masonry Walls and Buildings Using DEM." Structures 27 (June). Elsevier: 2274-2287. doi:10.1016/j.istruc.2020.08.026.

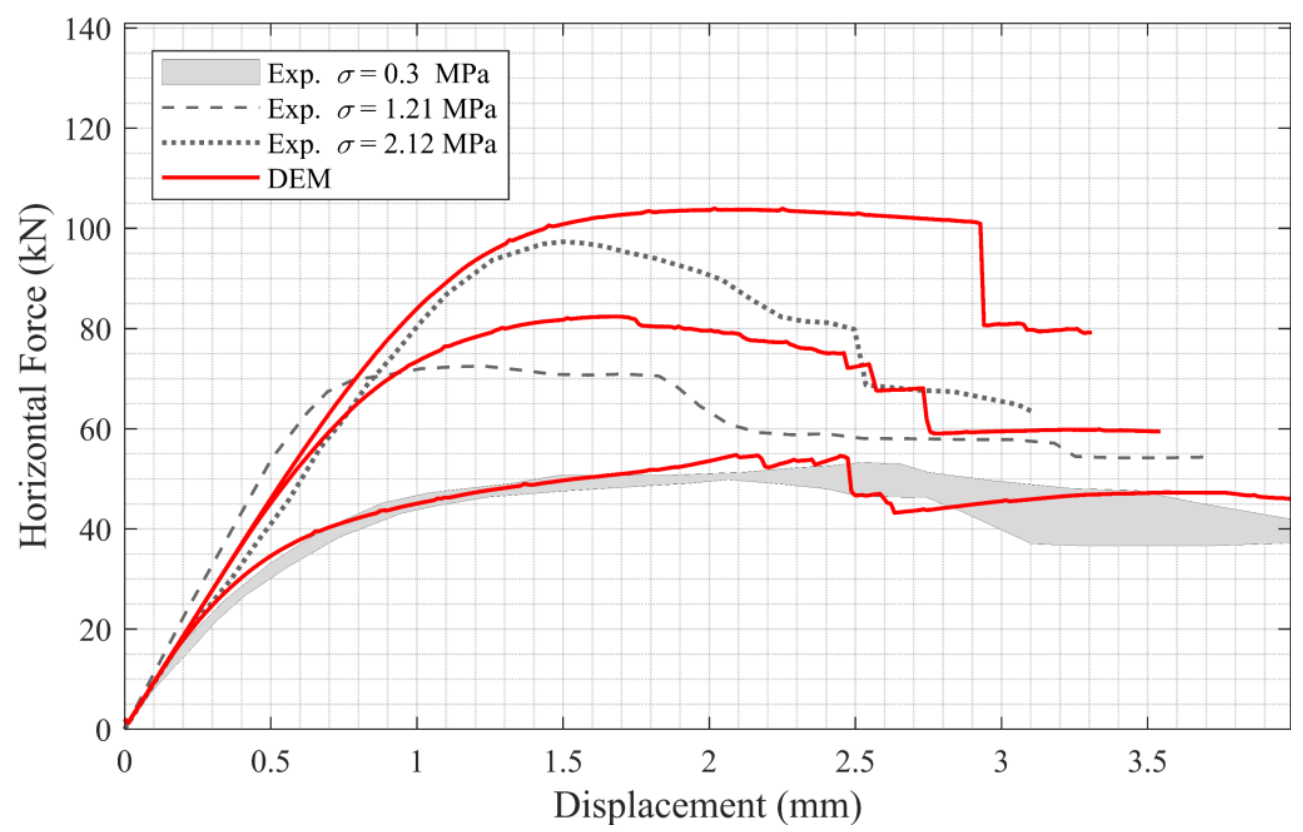

Figure 5. In-plane behavior of solid masonry walls subjected to different normal stress conditions: Experimental results vs. Numerical predictions (DEM).
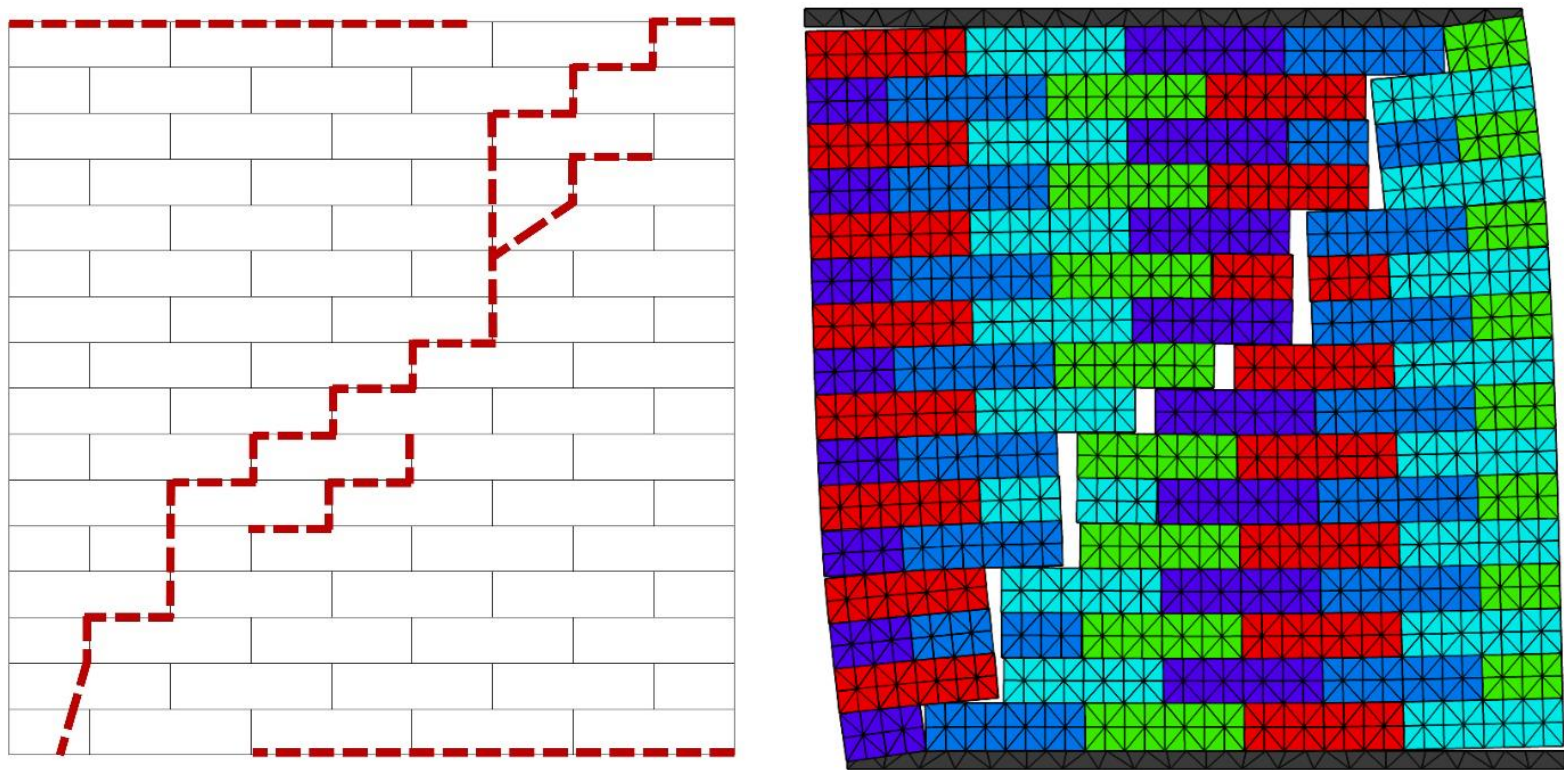

Figure 6. Collapse mechanism of URM shear wall; Experiment (Left) and Computational Model (Right).

Furthermore, the effect of prescribed nodal velocities on the macro-behavior of the discrete models is demonstrated in Figure 7a, considering moderate pre-compression stress ( $\sigma=$ $1.21 \mathrm{MPa}$ ). The oscillations at the results can be noted when the defined velocity condition is 10 
Preprint version, Reference: Pulatsu, Bora, Ece Erdogmus, Paulo B Lourenço, Jose V Lemos, and Kagan Tuncay. 2020. "Simulation of the In-Plane Structural Behavior of Unreinforced Masonry Walls and Buildings Using DEM." Structures 27 (June). Elsevier: 2274-2287. doi:10.1016/j.istruc.2020.08.026.

$1 \mathrm{~mm} / \mathrm{s}$, whereas there is no noticeable fluctuation and difference observed between the 2 displacement rates of 1 and $0.1 \mathrm{~mm} / \mathrm{s}$, as shown in Figure 7 . The same response is also noticed by 3 monitoring the ratio of unbalanced force $\left(F_{U B}\right)$ to total horizontal force $\left(F_{T}\right)$ during the analysis

4 (see Figure 7). It is clear that smaller velocities (i.e., $1 \mathrm{~mm} / \mathrm{s}$ and $0.1 \mathrm{~mm} / \mathrm{s}$ ) result in faster and 5 smoother convergence to the quasi-static solutions utilizing the Cundall's local damping 6 formulation (as mentioned earlier) and provide better numerical stability throughout the analyses.

7 On the contrary, it becomes difficult to damp the unbalanced forces in the system for relatively 8 higher velocities $(10 \mathrm{~mm} / \mathrm{s})$, which may delay the convergence or even may lead to the loss of 9 quasi-static equilibrium.
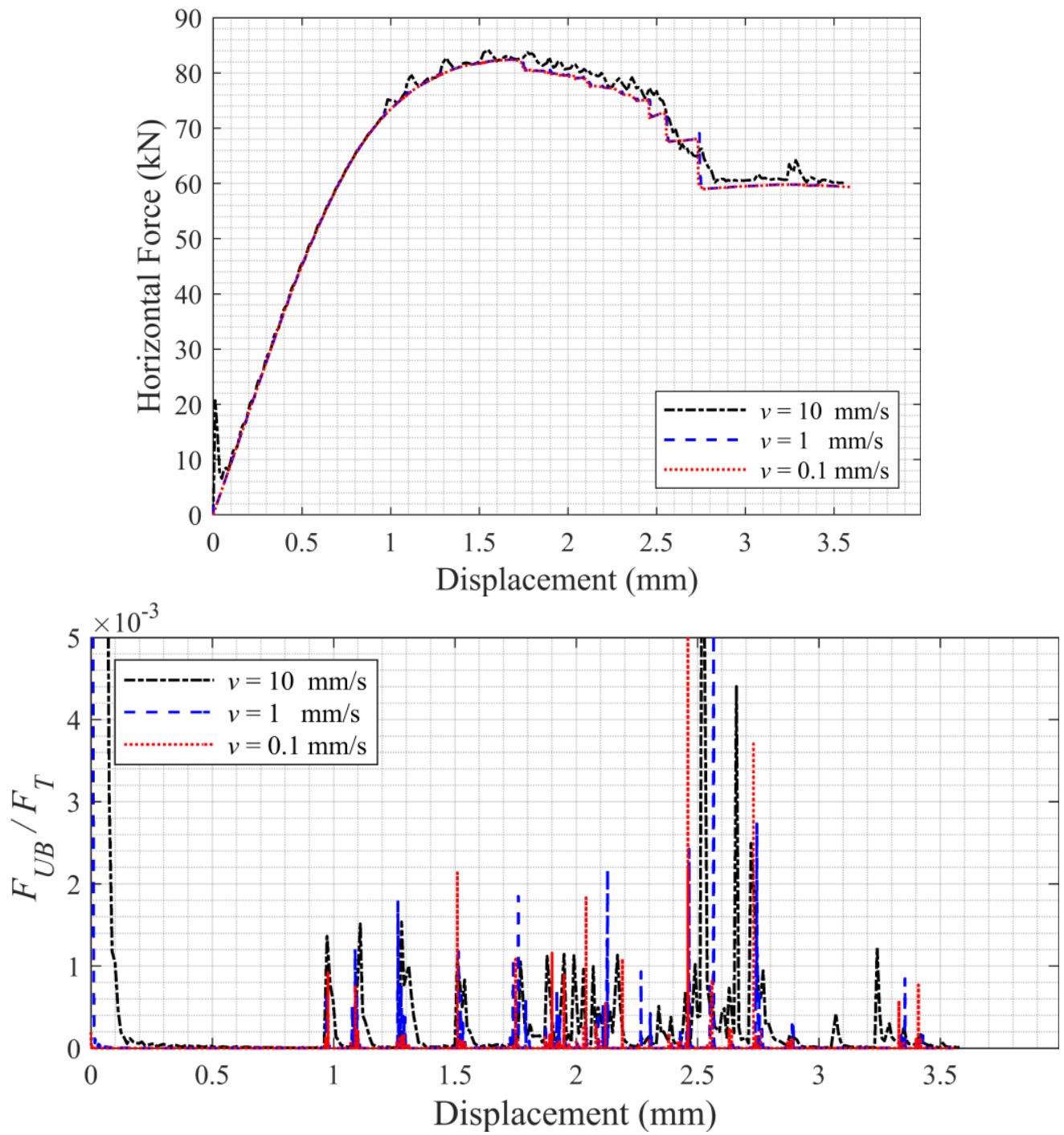

10 Figure 7. Top: Influence of the applied displacement rate on the macro response of the model $11(\sigma=1.21 \mathrm{MPa})$; Bottom: The ratio of unbalanced force $\left(F_{U B}\right)$ to total horizontal force $\left(F_{T}\right)$ history for different velocity boundary conditions. 
Preprint version, Reference: Pulatsu, Bora, Ece Erdogmus, Paulo B Lourenço, Jose V Lemos, and Kagan Tuncay. 2020. "Simulation of the In-Plane Structural Behavior of Unreinforced Masonry Walls and Buildings Using DEM." Structures 27 (June). Elsevier: 2274-2287. doi:10.1016/j.istruc.2020.08.026.

Additionally, it important to note that the brittle contact models are widely used in DEM

3 simulations, where the nonlinear post-peak response of the material (both for tension and shear) is

4 not considered. In other words, sudden stress drops to zero or a residual value after reaching the

5 defined strength values at the contact point is used in general. However, quasi-brittle materials

6 (e.g., concrete, masonry, rock, etc.) reveal a softening behavior under tensile and shear forces as

7 well as hardening/softening regime under compression. Therefore, to highlight the contribution

8 and effect of proposed softening contact models based on the fracture energy concept compare to

9 commonly used brittle contact models in DEM, the benchmark study is modeled via both contact

10 behaviors with the same strength properties. The results are shown in Figure 8. It is noted that the

11 brittle contact constitutive models, which is the standard contact law in 3DEC, may underestimate

12 the capacity and cause an irregular response during the analysis (Figure 8b), whilst the proposed

13 contact model provides better predictions and much more stable force-displacement curves.

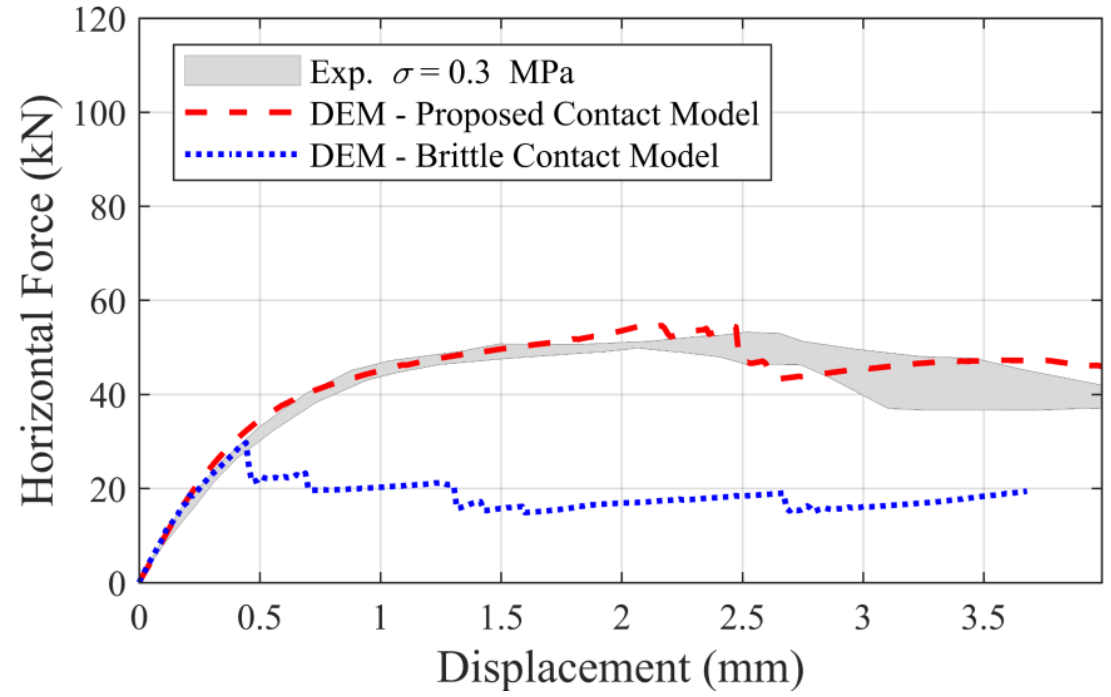

a) Horizontal force-displacement curves - Low stress level (0.3 MPa) 
Preprint version, Reference: Pulatsu, Bora, Ece Erdogmus, Paulo B Lourenço, Jose V Lemos, and Kagan Tuncay. 2020. "Simulation of the In-Plane Structural Behavior of Unreinforced Masonry Walls and Buildings Using DEM." Structures 27 (June). Elsevier: 2274-2287. doi:10.1016/j.istruc.2020.08.026.

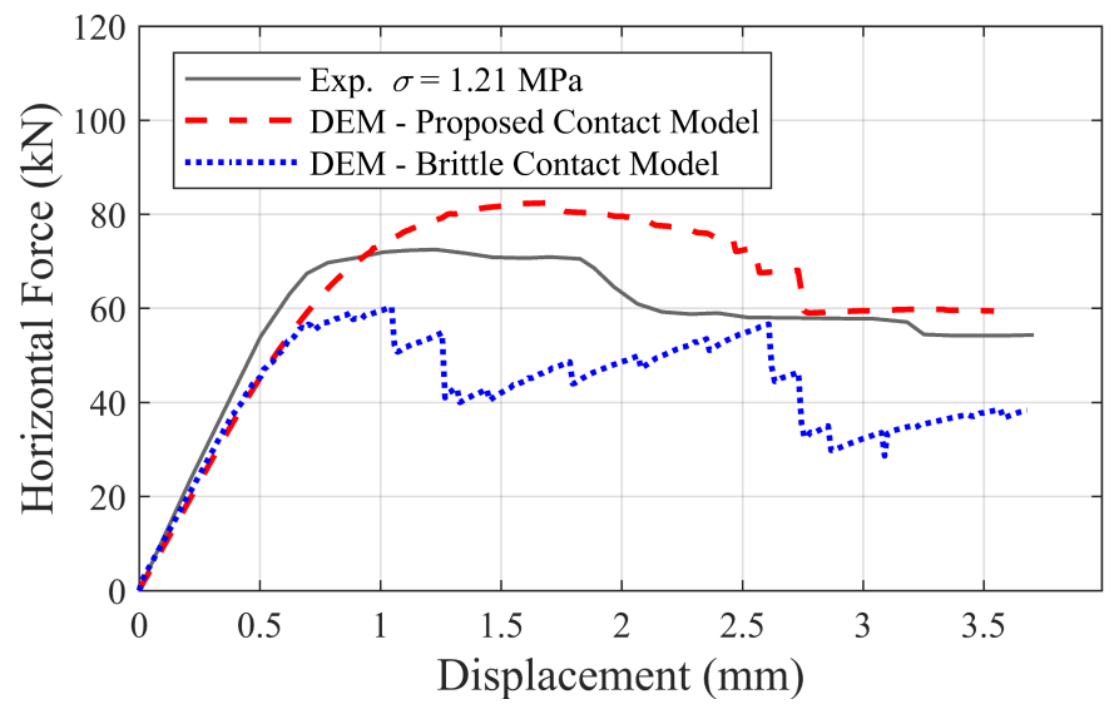

b) Horizontal force-displacement curves - Moderate stress level (1.21 MPa)

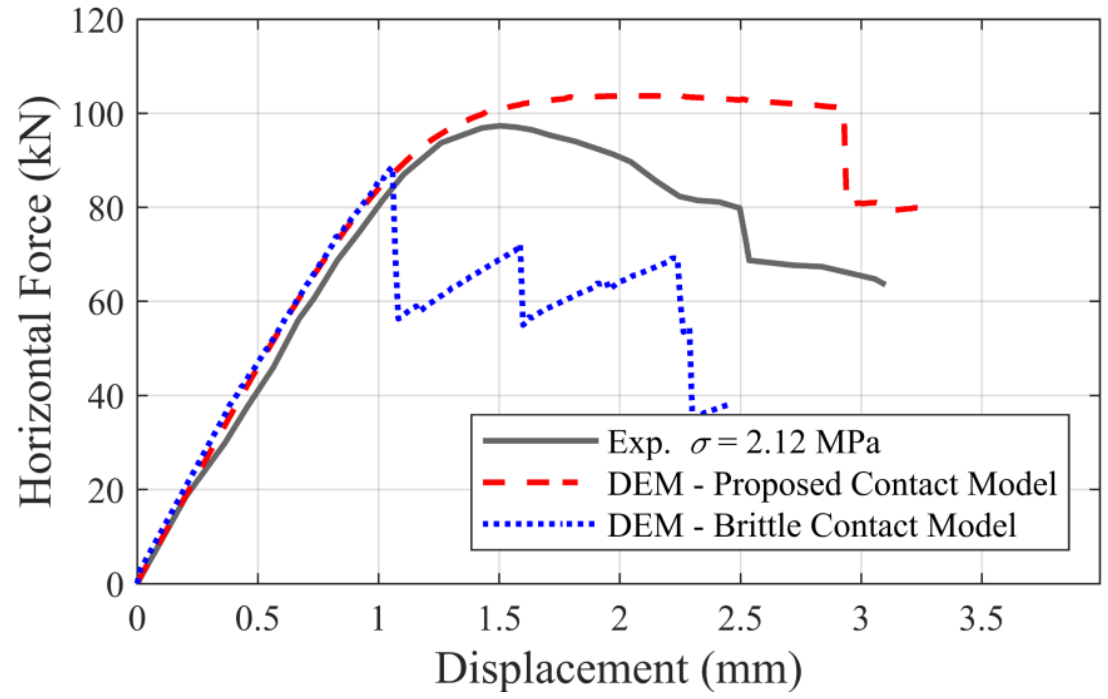

c) Horizontal force-displacement curves - High stress level (2.12 MPa)

Figure 8. Comparison of the standard contact model and the proposed fracture energy-based contact model in 3DEC.

To better understand the average relationship between the normal $(\sigma)$ and shear stresses $(\tau)$ in the macro-level, experimental capacities are compared with the computational predictions as well as the well-known failure criterion of Mann-Müller related to shear resistance [47]. The

7 friction Mann-Müller envelope, associated with the diagonal cracking along the unit-mortar 8 interfaces, is defined considering the joint parameters (unit-mortar interfaces) and initial normal 9 stress, as follows: 
Preprint version, Reference: Pulatsu, Bora, Ece Erdogmus, Paulo B Lourenço, Jose V Lemos, and Kagan Tuncay. 2020. "Simulation of the In-Plane Structural Behavior of Unreinforced Masonry Walls and Buildings Using DEM." Structures 27 (June). Elsevier: 2274-2287. doi:10.1016/j.istruc.2020.08.026.

$$
\tau=\frac{c_{j}}{1+\tan \phi_{j} \varphi}+\frac{\phi_{j}}{1+\tan \phi_{j} \varphi} \sigma
$$

where $c_{j}, \phi_{j}$ and $\varphi$ denote the joint cohesion, joint friction angle, and the parameter corresponding to the masonry pattern, which is calculated as $2 h / l$ ( $h$ and $l$ represent the height and length of the bricks). The shear strength parameters of the joints are taken from the benchmark study $\left(c_{j}=0.3 \mathrm{MPa}\right.$ and $\left.\tan \phi_{j}=0.7\right)$. Furthermore, the normal and shear (or tangential) stresses are computed, dividing the vertical forces and corresponding ultimate tangential loads by the wall gross cross-sectional area (bed joint area; $0.10 \times 0.99 \mathrm{~m}^{2}$ ). As can be depicted from Figure 9, the trend of the results exhibits the positive impact of the vertical pressure on the lateral resistance of the URM walls, and the experimental and numerical results show good agreement. In this study, both the initial and peak normal stress is considered. The linear least square regression, calculated based on the experimental results, indicates a good correlation $\left(R^{2}=0.99\right)$ with a relationship obtained as $\tau=0.45+0.24 \sigma$ for the initial value of the vertical stress and $\tau=0.25+0.36 \sigma$

$13\left(R^{2}=0.99\right)$ for the value of the vertical stress corresponding to the peak of the horizontal wall 14 strength, as shown in Figure 10. The obtained approximation gives a cohesion $c_{\text {wall }}=0.45 \mathrm{MPa}$ 15 where the normal stress is equal to zero, and a friction angle of 14 degrees $\left(\tan \phi_{\text {wall }}=0.25\right)$ for 16 the initial normal stress, which is incorrect, and a cohesion $c_{\text {wall }}=0.25 \mathrm{MPa}$, where the normal 17 stress is equal to zero, and a friction coefficient $\tan \phi_{w a l l}=0.36$ with the correct value of the normal stress. The friction Mann-Müller envelope gives a higher friction coefficient $\tan \phi_{\text {wall }}=$

190.52 together with a similar cohesion value of $c_{\text {wall }}=0.22 \mathrm{MPa}$ compared to the peak normal 20 stress regression (see Figure 10), because the tensile failure across the units is not included in 21 Equation 6. It is noted that close cohesion values are obtained between the wall and masonry unit 22 interface when the peak normal stresses are considered ( $c_{\text {wall }}=0.25 \mathrm{MPa}$ vs. $\left.c_{j}=0.30 \mathrm{MPa}\right)$, 23 which confirms the adequacy of the joint testing given in the European masonry code [48]. 24 Moreover, the obtained friction coefficient of the wall (tan $\left.\phi_{w a l l}\right)$ is also close to 0.4 as adopted 25 by current masonry design codes. Finally, it is noted that the obtained characteristic cohesion of 26 the walls, which can be computed by multiplying the average value by $0.8\left(c_{\text {wall }, k}=0.25 \times 0.8=\right.$ 27 0.20) is also in good agreement with Eurocode 6, which provides exactly the same value. 
Preprint version, Reference: Pulatsu, Bora, Ece Erdogmus, Paulo B Lourenço, Jose V Lemos, and Kagan Tuncay. 2020. "Simulation of the In-Plane Structural Behavior of Unreinforced Masonry Walls and Buildings Using DEM." Structures 27 (June). Elsevier: 2274-2287. doi:10.1016/j.istruc.2020.08.026.

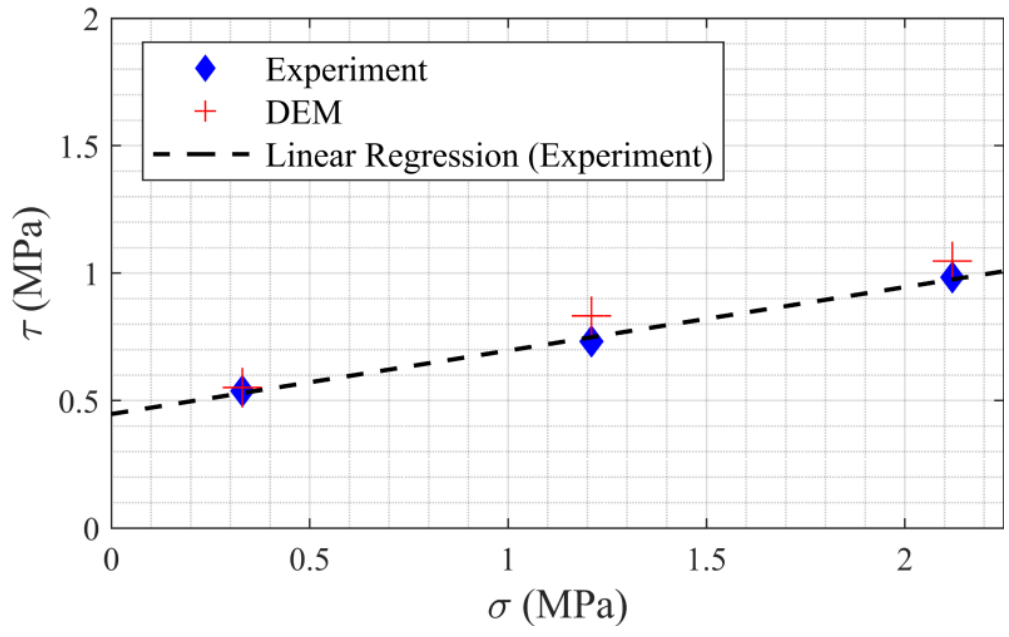

Figure 9. The relation between normal (initial) and tangential stresses in the solid masonry walls: Experimental results and DEM.

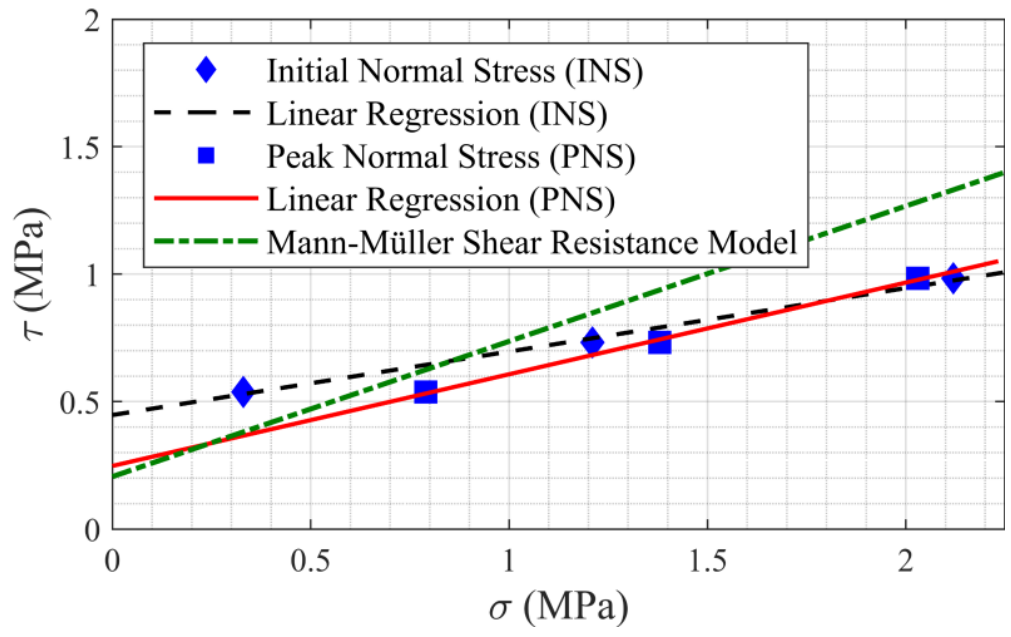

Figure 10. Influence of the initial and peak normal stresses on the normal and shear stress relationship of solid masonry walls.

Next, the hollow wall experiment is analyzed with the same material and contact properties as given earlier. Before the horizontal loading, a vertical pressure $(0.30 \mathrm{MPa})$ is applied to replicate the experimental setup. There is no joint defined at the mid-section of the masonry units since the experiments indicate the crack localization occurs at the mortar joints rather than the clay bricks due to low vertical pre-compression. In Figure 11, the numerical solution is compared with the experimental envelope, where the force-displacement response is in line with the experimental 
Preprint version, Reference: Pulatsu, Bora, Ece Erdogmus, Paulo B Lourenço, Jose V Lemos, and Kagan Tuncay. 2020. "Simulation of the In-Plane Structural Behavior of Unreinforced Masonry Walls and Buildings Using DEM." Structures 27 (June). Elsevier: 2274-2287. doi:10.1016/j.istruc.2020.08.026.

1 results. Moreover, a similar collapse mechanism is predicted by the computational model, 2 confirming the stair-step cracks, starting from the top and bottom corners of the opening and 3 penetrating towards the edges of the masonry wall, as shown in Figure 12.

4 In conclusion, the results obtained with the solid and hollow masonry shear walls show 5 that the proposed non-linear contact models implemented in the discrete element formulation not 6 only capture the load-displacement curve of URM walls accurately, but also capture the correct 7 collapse mechanism, including joint opening, sliding, and crushing phenomena.

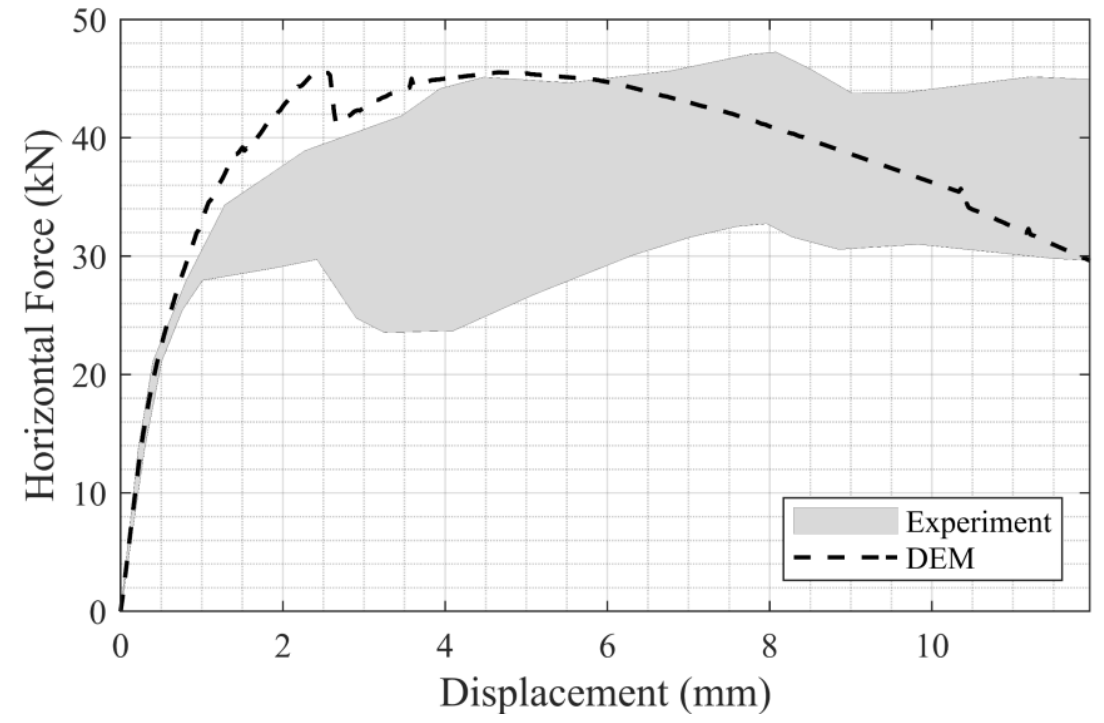

9 Figure 11. Force displacement response of a hollow masonry wall: Experimental envelop vs. DEM. 
Preprint version, Reference: Pulatsu, Bora, Ece Erdogmus, Paulo B Lourenço, Jose V Lemos, and Kagan Tuncay. 2020. "Simulation of the In-Plane Structural Behavior of Unreinforced Masonry Walls and Buildings Using DEM." Structures 27 (June). Elsevier: 2274-2287. doi:10.1016/j.istruc.2020.08.026.
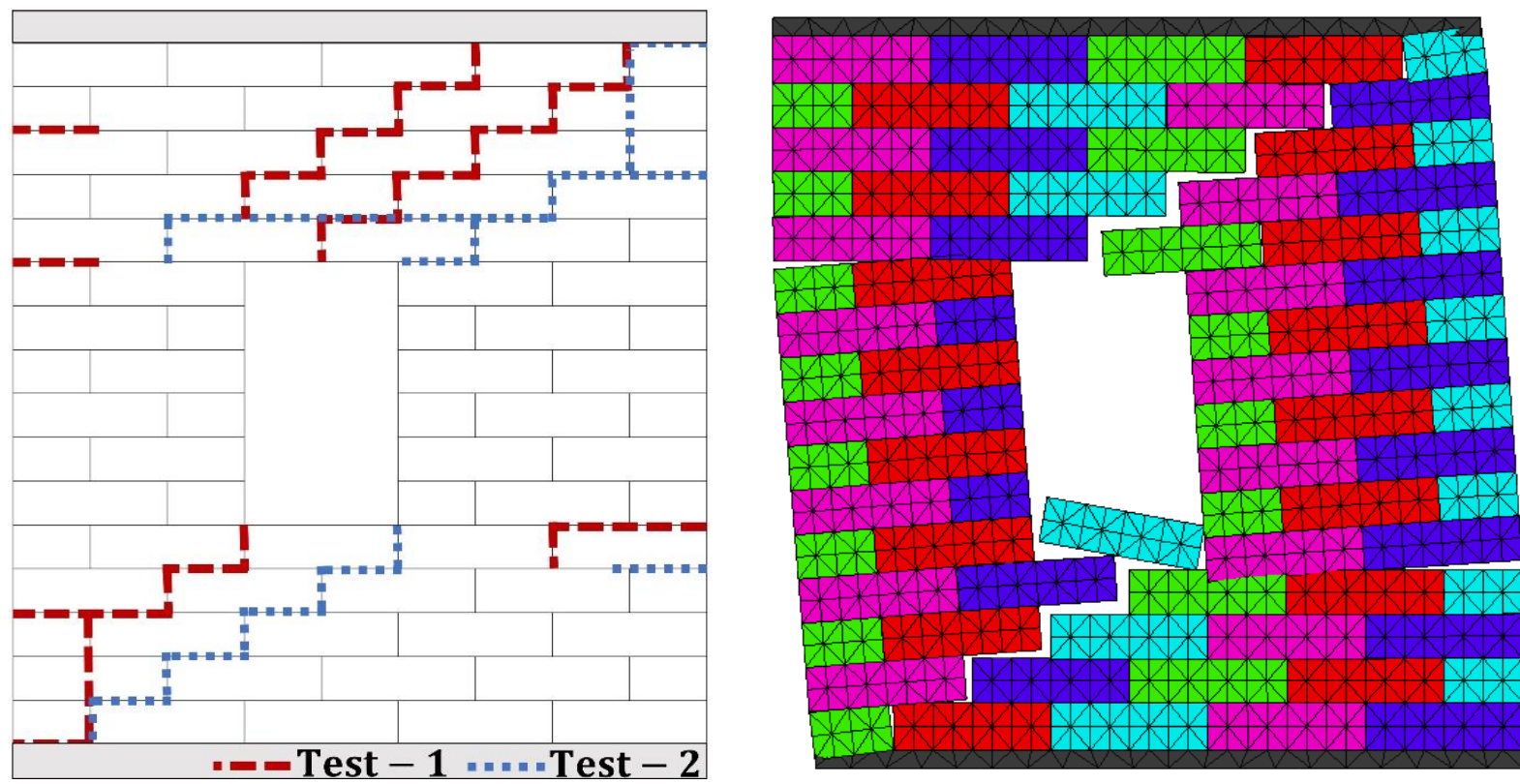

Figure 12. Collapse mechanism of hollow URM shear wall; Left: Experimental failure patterns; Right: Proposed computational modeling.

\section{Parametric Analysis}

It is often difficult to estimate the actual mechanical properties of an existing masonry structure, as masonry structures have highly non-uniform material characteristics. As a result of this, sensitivity analyses help to explore the influence of elastic and non-linear contact parameters and overcome the effects of these uncertainties. In this section, the sensitivity of results with respect to the modeling options are investigated considering the number of contact points, contact stiffness, size (or number) of the masonry units, and fracture energy. The results should be fairly independent of modeling decisions (contact points, contact stiffness, and the number of masonry units), avoiding to add these epistemic uncertainties to the stated aleatoric uncertainties in material properties (including namely fracture energy, which is a material property less studied than masonry strength properties).

Number of contact points: In DEM, the contact stresses are calculated based on the relative contact displacements among adjacent blocks. To obtain an accurate stress distribution along the contact surface, a sufficient number of contact points are required. In the reference model, there are 10 contact points considered along the horizontal edge of a single masonry unit, consisting of two 
Preprint version, Reference: Pulatsu, Bora, Ece Erdogmus, Paulo B Lourenço, Jose V Lemos, and Kagan Tuncay. 2020. "Simulation of the In-Plane Structural Behavior of Unreinforced Masonry Walls and Buildings Using DEM." Structures 27 (June). Elsevier: 2274-2287. doi:10.1016/j.istruc.2020.08.026.

1 discrete blocks with a contact surface at the mid-section. Hence, each half-masonry unit has 5 contact points along its horizontal edge and discretized into 80 tetrahedral volumes. The effect of the contact point is analyzed, considering three discretization schemes, namely low (B2T4), moderate (B2T8), and fine (B2T16), as indicated in Figure 13. Note that the discretization names are given based on the number of tetrahedral volumes that each half-masonry unit contains. It can be seen that the results are basically insensitive to the number of contact points between the moderate and fine discretization, whereas using inadequate contact points cause some overestimation of the capacity. Therefore, it is suggested to employ at least the moderate contact discretization in discrete element models to obtain accurate results.
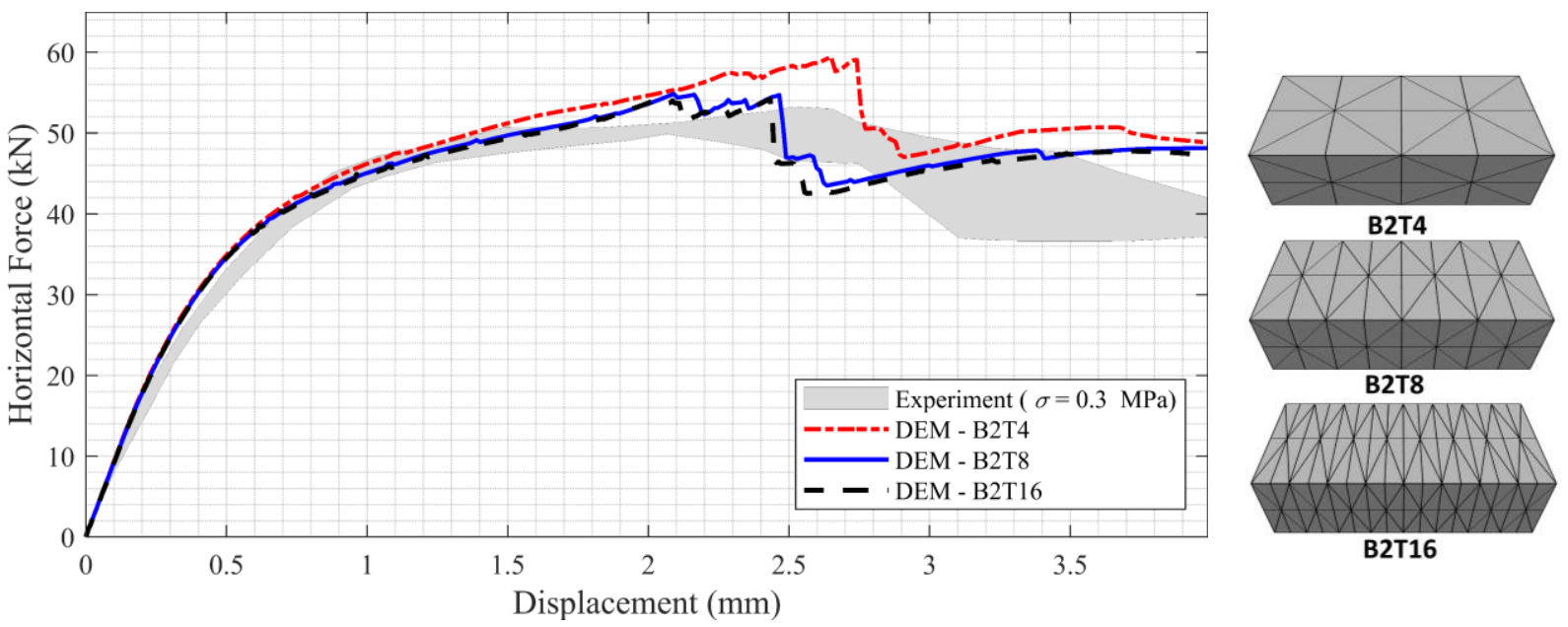

Figure 13. Effect of the number of contacts on the macro behavior of the numerical models.

13 Contact stiffness: For most URM structures, elastic stiffness of the masonry units is higher than

14 the mortar and unit-mortar interface elastic stiffness, meaning stiff brick and soft mortar action.

15 To better understand the effect of the contact stiffness, defined at the mid-section of the masonry 16 units, a sensitivity analysis is performed on the validated model. During the analysis, contact 17 stiffness ratio, $\left(k_{n}\right)_{u} /\left(k_{n}\right)_{j}$, is varied from 1 to 10 by increasing the contact stiffness of the joint 18 within the masonry units. According to the results of the analyses, the force-displacement response 19 of the shear walls subjected to the moderate stress level of pre-compression (1.21 MPa) become 20 identical when the contact stiffness ratio gets higher than four (Figure 14), which yield stiff brick 21 with soft mortar action. Hence, in the case of insufficient data for masonry unit properties, the 
Preprint version, Reference: Pulatsu, Bora, Ece Erdogmus, Paulo B Lourenço, Jose V Lemos, and Kagan Tuncay. 2020. "Simulation of the In-Plane Structural Behavior of Unreinforced Masonry Walls and Buildings Using DEM." Structures 27 (June). Elsevier: 2274-2287. doi:10.1016/j.istruc.2020.08.026.

1 contact stiffness determined within the masonry units can be estimated as four times the interface stiffness.

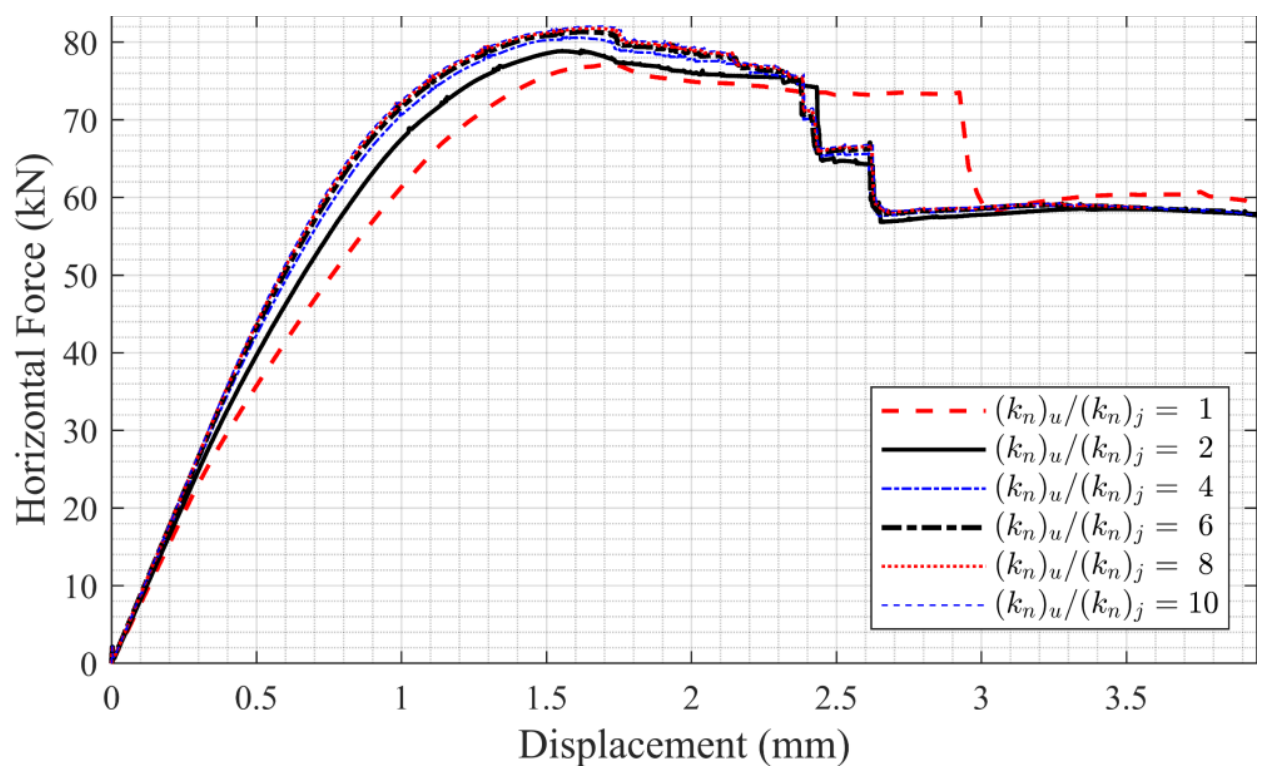

Figure 14. Influence of the contact stiffness ratio $\left(\left(k_{n}\right)_{u} /\left(k_{n}\right)_{j}\right)$ on the force-displacement behavior (Adopted pre-compression, $\sigma=1.21 \mathrm{MPa}$ ).

Size of the discrete blocks: Often, in large scale models, a single discrete block represents more than one actual masonry unit to prevent impractical computational costs [20]. Hence, to get insight into the effect of the size adopted for discrete blocks, an identical test setup is prepared, considering a $2 m \times 2 m$ solid wall, two times bigger than the benchmark experiment. Initially, the URM wall

11 is subjected to a moderate pre-compression $(1.21 \mathrm{MPa})$, then exposed to lateral forces through the 12 upper edge of the wall. Four different block sizes with similar aspect ratios are considered, yielding 1360 and 576 discrete blocks for the coarse and fine models, respectively. In the case of 576 blocks,

14 the blocks' size is taken as similar to the benchmark study to replicate real size masonry units.

15 Note that identical contact parameters, as employed in the benchmark study, are considered, except

16 for the contact stiffnesses, which are decreased proportionally when the block sizes become larger

17 to obtain the same structural stiffness of the wall. For instance, the vertical spacing of the reference blocks $\left(h_{b}^{r e f}\right)$ and the normal contact stiffness, $\left(k_{n}^{r e f}\right)_{j}$, used in the benchmark study, are utilized 
Preprint version, Reference: Pulatsu, Bora, Ece Erdogmus, Paulo B Lourenço, Jose V Lemos, and Kagan Tuncay. 2020. "Simulation of the In-Plane Structural Behavior of Unreinforced Masonry Walls and Buildings Using DEM." Structures 27 (June). Elsevier: 2274-2287. doi:10.1016/j.istruc.2020.08.026.

1 to estimate the normal contact stiffness $\left(k_{n}^{*}\right)$ for the larger blocks based on the new vertical spacing $2 \quad\left(h_{b}^{*}\right)$, as $\left(k_{n}^{*}\right)_{j}=h_{b}^{*}\left(k_{n}^{r e f}\right)_{j} / h_{b}^{r e f}$.

As shown in Figure 15, results do not demonstrate a significant dependency on the block 4 size in the discrete element models. It is also worth noting that the difference of the ultimate 5 capacity of the wall between the models with various block sizes only varies by less than $6 \%$. 6 Although slightly different trends are observed in the force-displacement responses, a consistent 7 reduction of the peak load is obtained with an increasing number of blocks, where the capacity 8 difference becomes almost negligible between 240 and 576 blocks (see Figure 15a). On the other 9 hand, a similar failure mechanism is obtained for all analyzed masonry walls, in which tension and 10 shear failures concentrate diagonally and crushing failures concentrate at the bottom left and top 11 right corners (see Figure 15b). These results also imply that the proposed modeling strategy can 12 be applied to larger-scale URM structures with small differences in terms of strength when the 13 block size is four times of the actual geometry in real masonry panels (size of $2 \mathrm{~m} \times 2 \mathrm{~m}$ is 14 considered here), which is demonstrated in the following section. Furthermore, from the 15 computational cost point of view, to obtain full stress-displacement curve (e.g., Figure 15a) 16 requires 16 and 140 minutes for coarse and fine discontinuum models, respectively, using a 17 computer system with Intel(R) Xeon(R) CPU @ $2.1 \mathrm{GHz}$ processor and 128 GB memory RAM. 
Preprint version, Reference: Pulatsu, Bora, Ece Erdogmus, Paulo B Lourenço, Jose V Lemos, and Kagan Tuncay. 2020. "Simulation of the In-Plane Structural Behavior of Unreinforced Masonry Walls and Buildings Using DEM." Structures 27 (June). Elsevier: 2274-2287. doi:10.1016/j.istruc.2020.08.026.

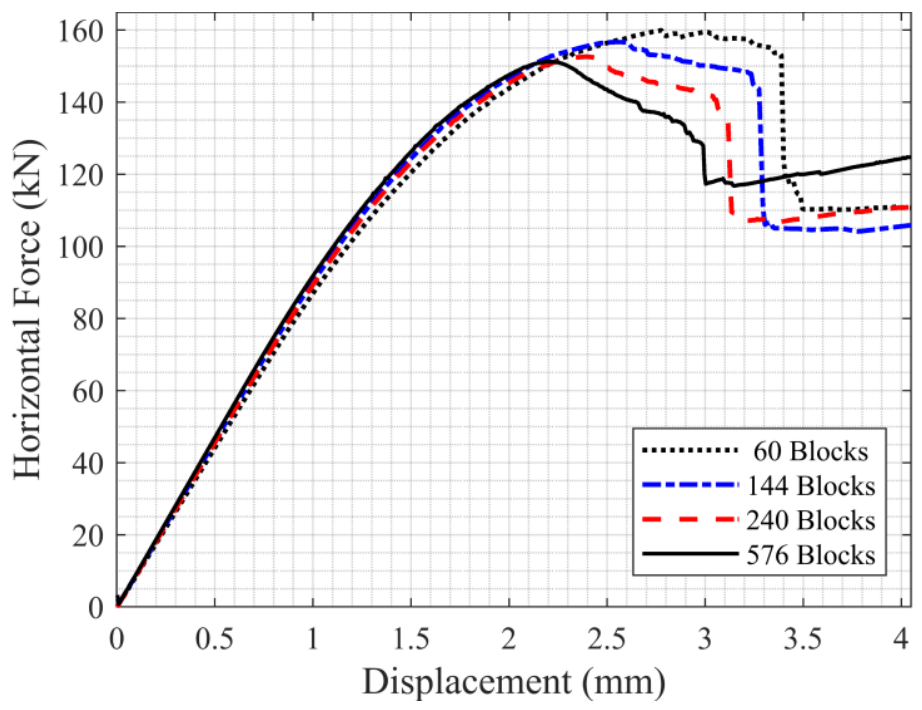

a) Force-displacement behavior of URM walls consisting of different number of discrete blocks.
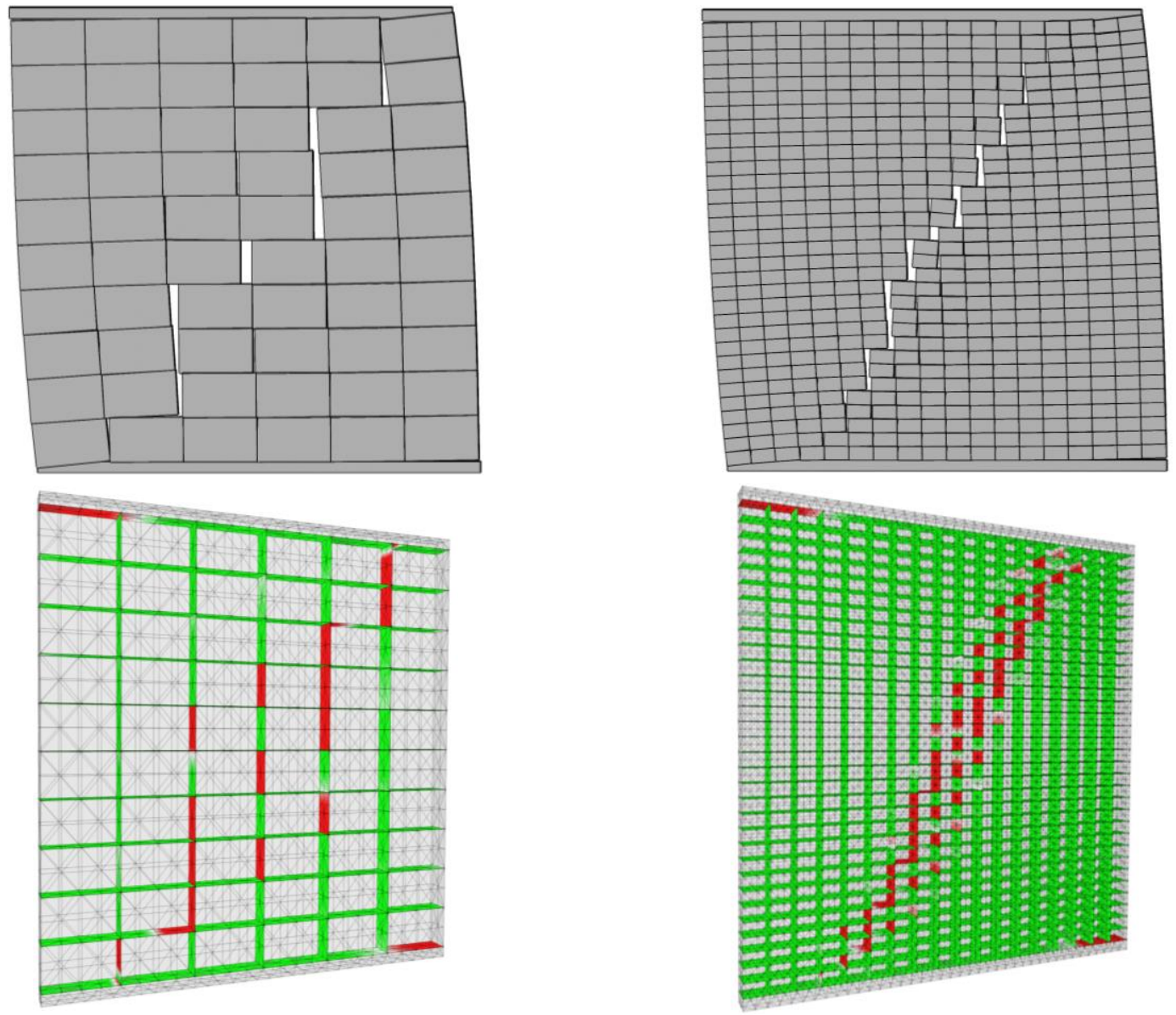

Damage

$$
1
$$

b) Left: 60 blocks, Right: 576 blocks (Tensile damage at the contact surfaces).

Figure 15. Influence of the block size on the macro-behavior of the masonry wall. 
Preprint version, Reference: Pulatsu, Bora, Ece Erdogmus, Paulo B Lourenço, Jose V Lemos, and Kagan Tuncay. 2020. "Simulation of the In-Plane Structural Behavior of Unreinforced Masonry Walls and Buildings Using DEM." Structures 27 (June). Elsevier: 2274-2287. doi:10.1016/j.istruc.2020.08.026.

2 Fracture Energy: Proposed contact-constitutive models for tension, shear, and compression 3 include the corresponding fracture energies that can be obtained experimentally or estimated based 4 on the available data in the literature $[49,50]$. To test the fracture energy dependency of the results, 5 different values of $G_{f}^{I}$ and $G_{f}^{I I}$ are used for the unit-mortar interfaces in the solid wall model that 6 is subjected to moderate pre-compression of 1.21 MPa (validated with the benchmark study). The 7 sensitivity analyses reveal the evident influence of the fracture energy concept defined at each 8 contact point, as presented in Figure 16. When the fracture energy gets higher, shear walls 9 demonstrate higher ductility, whereas there is no considerable increase found in terms of the 10 capacity (less than $10 \%$ ). Furthermore, quite similar collapse mechanisms are obtained from the 11 sensitivity analyses.

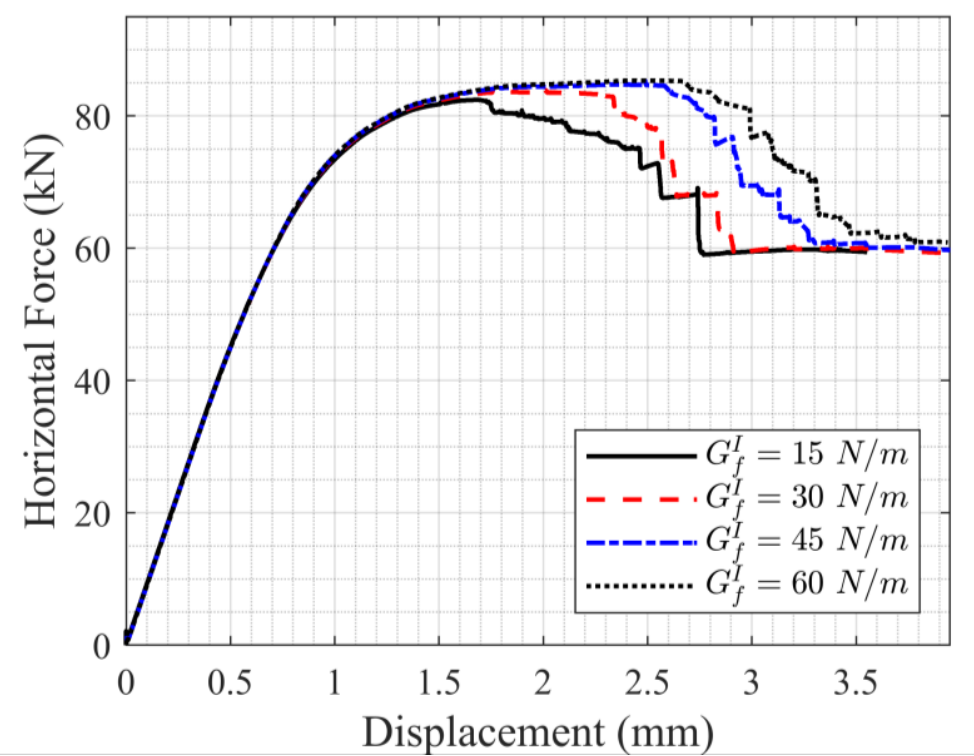

a) Sensitivity analysis - $G_{f}^{I}\left(G_{f}^{I I}=125 \mathrm{~N} / \mathrm{m}\right)$ 
Preprint version, Reference: Pulatsu, Bora, Ece Erdogmus, Paulo B Lourenço, Jose V Lemos, and Kagan Tuncay. 2020. "Simulation of the In-Plane Structural Behavior of Unreinforced Masonry Walls and Buildings Using DEM." Structures 27 (June). Elsevier: 2274-2287. doi:10.1016/j.istruc.2020.08.026.

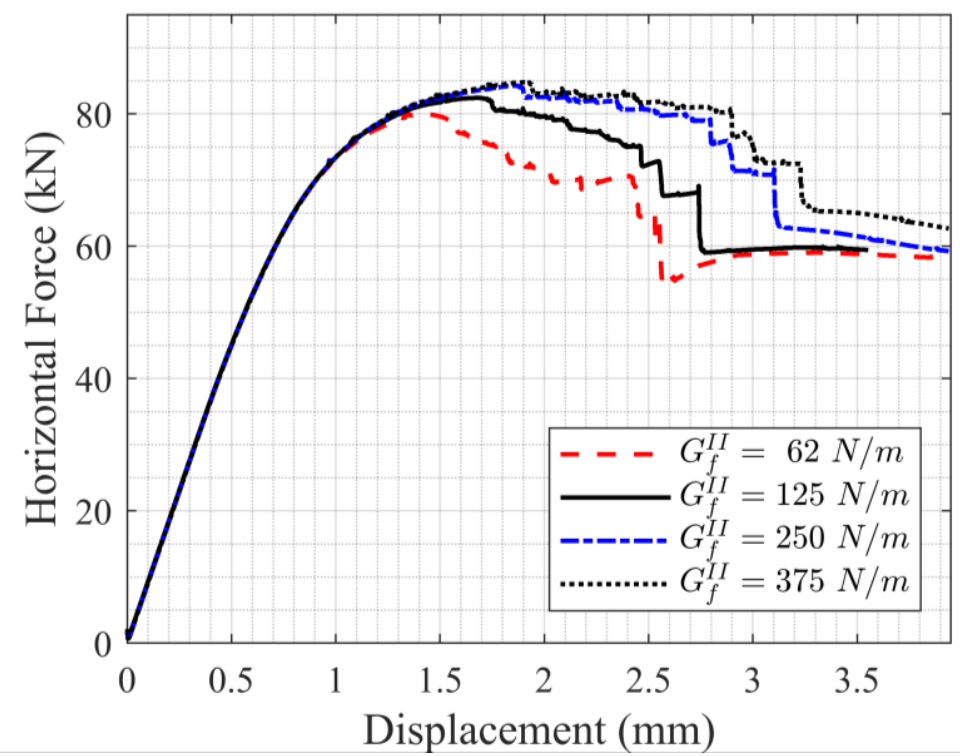

b) Sensitivity analysis - $G_{f}^{I I}\left(G_{f}^{I}=15 \mathrm{~N} / \mathrm{m}\right)$

Figure 16. Influence of the fracture energy at the contact point between masonry units on the macro behavior of the masonry walls.

\section{Validation: Full-Scale URM Building}

In this section, the validated modeling strategy is further used to explore the seismic response of a full-scale URM building. Discrete element models are compared with the experimental results presented by Magenes et al. [51], in which a full-scale two-story URM building, built by solid fired-clay bricks with hydraulic lime mortar, was tested under cyclic loading. The tested building had a total wall height of $6.4 \mathrm{~m}$ and a wall thickness of $0.25 \mathrm{~m}$, with non-symmetric openings. The plan view dimensions of the building were $6 m \times 4 m$. It is important to note that wall D (referred to as door wall) was not connected to the transverse walls A and C, whereas wall B (referred to as window wall) was connected to the adjacent walls considering an interlocking brick pattern around the corners, which are shown in Figure 17a separately. Therefore, in practice, the test setup was composed of two individual shear walls (door and window walls) with no coupling effect due to a non-interlocking brick pattern around the corners. Eleven isolated steel beams were used to provide a very flexible floor diaphragm. The gravity and horizontal loads were applied through the floor beams that are represented in the numerical model as points loads, given in Figure 17b. Additional concrete blocks were used to apply vertical loads of $248.4 \mathrm{kN}$ and $236.8 \mathrm{kN}$ for

the first and second floors, respectively. During the experiment, the seismic forces were simulated, 
Preprint version, Reference: Pulatsu, Bora, Ece Erdogmus, Paulo B Lourenço, Jose V Lemos, and Kagan Tuncay. 2020. "Simulation of the In-Plane Structural Behavior of Unreinforced Masonry Walls and Buildings Using DEM." Structures 27 (June). Elsevier: 2274-2287. doi:10.1016/j.istruc.2020.08.026.

1 considering four concentrated forces for each floor (at the two longitudinal walls) and floor-beam 2 intersections via displacement-controlled screw jacks. For further details about the experimental 3 setup and testing procedure, readers are referred to [51].
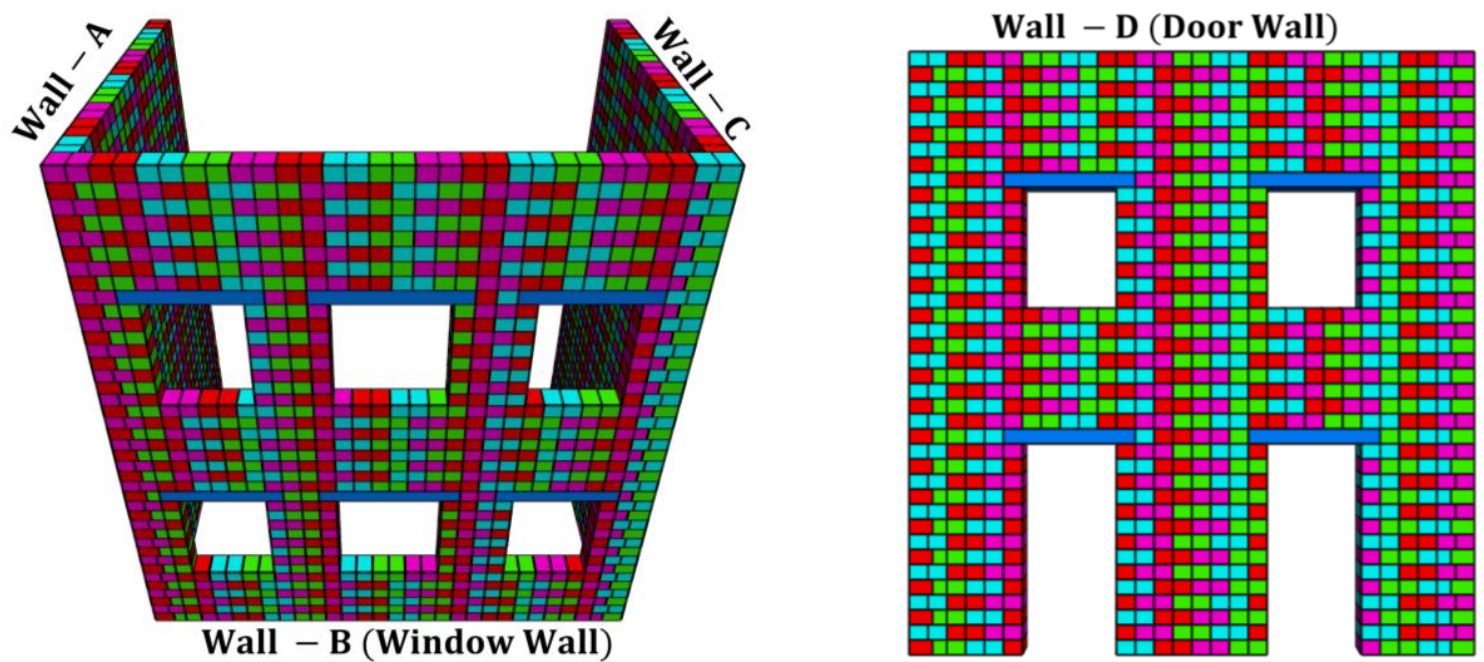

a) Full-scale masonry building URM walls system $A+B+C$ (Left), Door wall (Right).
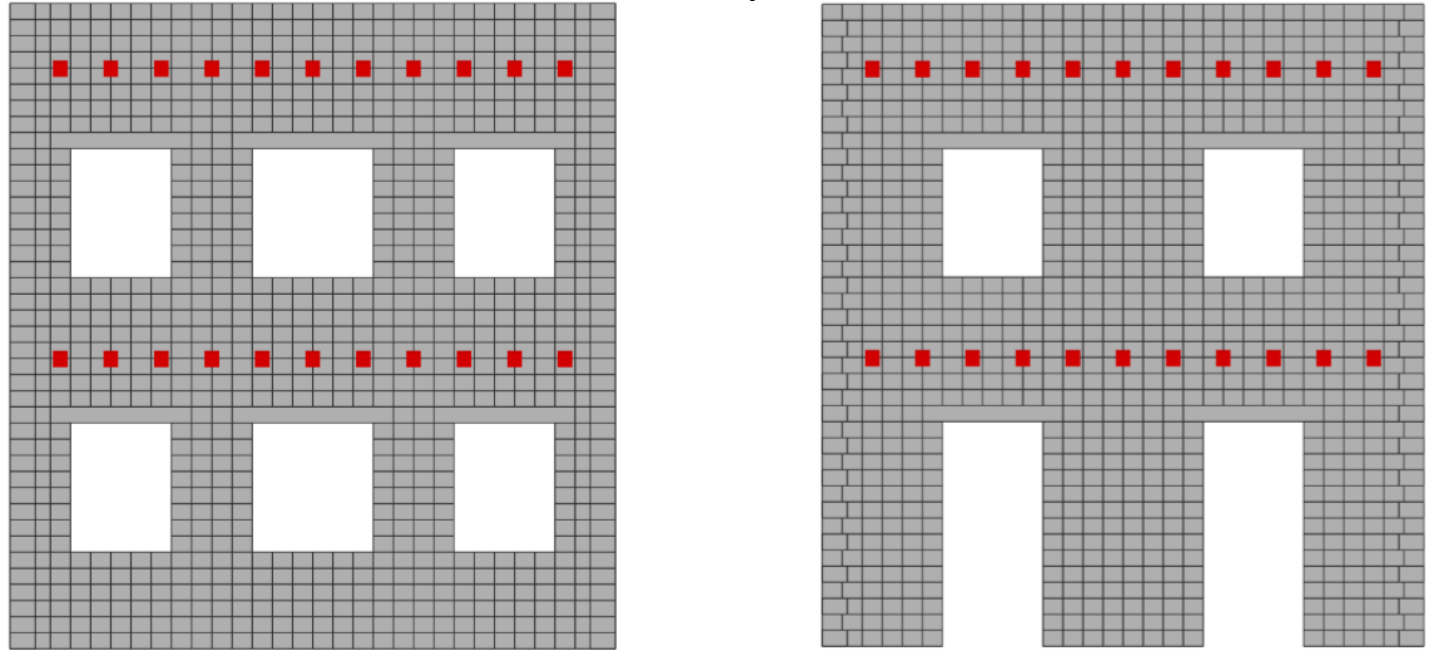

b) Front view of the window (left) and door (right) walls together with the floor beam locations, as small squares.

Figure 17. Illustration of the URM building using discrete element models.

Two separate models consisting of wall A (door wall) and a combination of wall A, B (window wall), and C are analyzed individually. URM walls are represented as a system of discrete blocks

9 that can mechanically interact with each along their boundaries, and masonry units are replicated 10 as elastic continuum blocks with a potential crack surface at the mid-section. In Table 2, the 
Preprint version, Reference: Pulatsu, Bora, Ece Erdogmus, Paulo B Lourenço, Jose V Lemos, and Kagan Tuncay. 2020. "Simulation of the In-Plane Structural Behavior of Unreinforced Masonry Walls and Buildings Using DEM." Structures 27 (June). Elsevier: 2274-2287. doi:10.1016/j.istruc.2020.08.026.

1 number of blocks and zones that are used for each discrete element model can be found. Each 2 independent model is subjected to a monotonically increasing lateral force at the points matching 3 with the locations of the horizontal loads applied during the testing.

Table 2. The number of blocks and zones used in the large-scale discrete element model.

\begin{tabular}{|c|c|c|}
\hline Wall & D & A+B+C \\
\hline Number of blocks & 996 & 2506 \\
\hline Number of zones & 81600 & 203360 \\
\hline
\end{tabular}

The contact stiffness $\left(k_{n}\right)$ is calculated using Equation 7, where $h$ indicates the vertical joint 8 spacing, and $E$ denotes the elastic stiffness (Young's modulus) of masonry. Furthermore, the 9 elastic stiffness of the continuum blocks is defined as $2.4 \mathrm{GPa}[52,53]$. The vertical joint spacing 10 in the discrete element model is determined as $0.16 \mathrm{~m}$. Compressive strength of the masonry prism $11\left(f_{m}^{\prime}\right)$ was obtained from the material testing and provided as 6.2 MPa [51]. It important to note that 12 it is difficult to estimate the stiffness of the masonry based on its compression strength due to the 13 high variability in the experimental data, which can be expressed considering lower and upper 14 bounds of $200 f_{m}^{\prime}$ and $350 f_{m}^{\prime}$ for lime mortar - clay brick masonry, as discussed in [54,55]. In this 15 study, Young's modulus of the masonry is approximately estimated based on the mean 16 compression strength of masonry prism as $E_{\text {masonry }} \approx 225 f_{c}^{\prime}$.

$$
\frac{1}{E_{\text {masonry }}}=\frac{1}{E_{\text {unit }}}+\frac{1}{\left(k_{n} h\right)}
$$

Note that depending on the availability of the experimental data, some parameters are taken

20 from experimental results, whereas other parameters are estimated, considering [56], and similar 21 studies [46,57]. The contact properties are given in Table 3. The contact stiffness ratio between 22 units and joints is taken as six based on the parametric analysis discussed in the previous section. 
Preprint version, Reference: Pulatsu, Bora, Ece Erdogmus, Paulo B Lourenço, Jose V Lemos, and Kagan Tuncay. 2020. "Simulation of the In-Plane Structural Behavior of Unreinforced Masonry Walls and Buildings Using DEM." Structures 27 (June). Elsevier: 2274-2287. doi:10.1016/j.istruc.2020.08.026.

Table 3. Contact properties - Masonry Building

\begin{tabular}{|c|c|c|c|c|}
\hline \multicolumn{5}{|c|}{ Interaction within the masonry units (bricks) } \\
\hline$\left(k_{n}\right)_{u}(G P a / m)$ & $\left(k_{s}\right)_{u}(G P a / m)$ & $f_{t}(M P a)$ & $c(M P a)$ & $\phi_{0}\left({ }^{\circ}\right)$ \\
\hline 120 & 50 & 1 & 1.5 & 35 \\
\hline$\theta_{\text {res }}\left(^{\circ}\right)$ & $f_{c}(M P a)$ & $G_{f}^{I}(N / m)$ & $G_{f}^{I I}(N / m)$ & $G_{c}(N / m)$ \\
\hline 35 & 15 & 80 & 125 & 20640 \\
\hline \multicolumn{5}{|c|}{ Interaction between the masonry units (unit-mortar interface) } \\
\hline$\left(k_{n}\right)_{j}(G P a / m)$ & $\left(k_{s}\right)_{j}(G P a / m)$ & $f_{t}(M P a)$ & $c(M P a)$ & $\phi_{0}\left(^{\circ}\right)$ \\
\hline 20 & 8.3 & 0.05 & 0.075 & 30 \\
\hline$\theta_{\text {res }}\left(^{\circ}\right)$ & $f_{c}(M P a)$ & $G_{f}^{I}(N / m)$ & $G_{f}^{I I}(N / m)$ & $G_{c}(N / m)$ \\
\hline 30 & 6.2 & 5 & 20 & 10000 \\
\hline
\end{tabular}

The results of the cyclic test are presented in Figure 18, which indicates the cyclic response of the tested building by means of the base shear versus roof displacements and corresponding cyclic envelopes for the two independent structural systems. Additionally, numerical predictions are compared with the cyclic envelopes in Figure 19. In general, there is a good agreement between the computational models and the experimental findings in terms of capacity (Figure 19) and the collapse mechanisms (Figure 20). While the lateral capacity of the door wall (Wall D) is predicted

9 with a negligible difference, the other wall system (Wall $\mathrm{A}+\mathrm{B}+\mathrm{C}$ ) is slightly overestimated 10 (approximately 15\%). However, this difference is the likely result of loading protocol differences, 11 namely monotonic vs. cyclic, as well as the non-uniform distribution of the material properties.
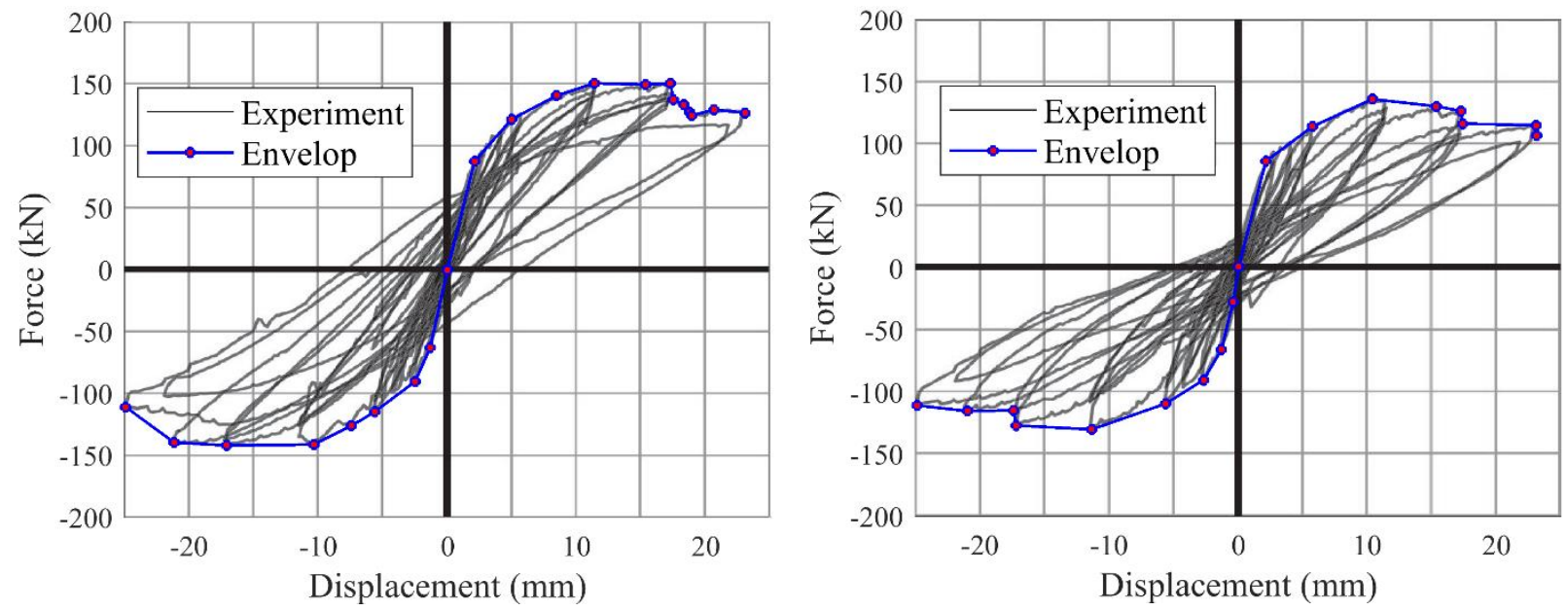
Preprint version, Reference: Pulatsu, Bora, Ece Erdogmus, Paulo B Lourenço, Jose V Lemos, and Kagan Tuncay. 2020. "Simulation of the In-Plane Structural Behavior of Unreinforced Masonry Walls and Buildings Using DEM." Structures 27 (June). Elsevier: 2274-2287. doi:10.1016/j.istruc.2020.08.026.

Figure 18. Cyclic response of the door wall (left) and combined system of walls A, B (window wall), and C (right) [51].

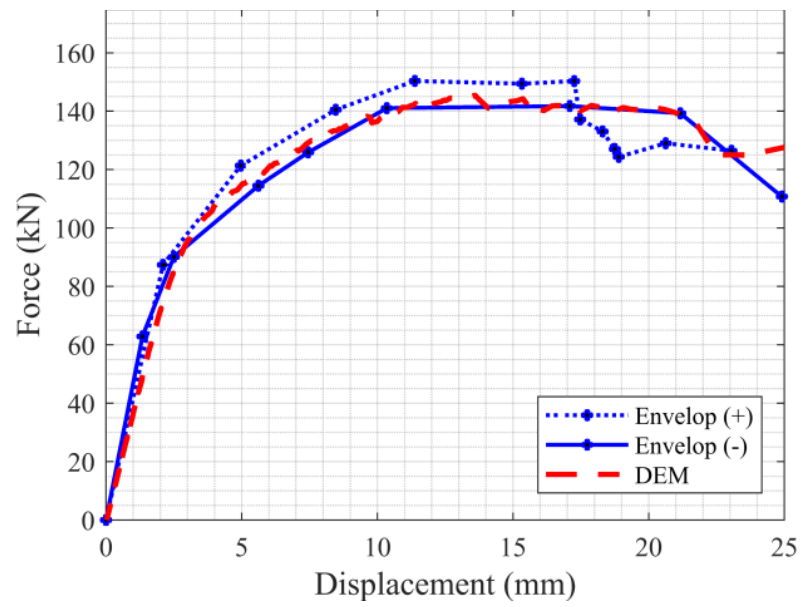

a) Experimental results vs. DEM - Door Wall

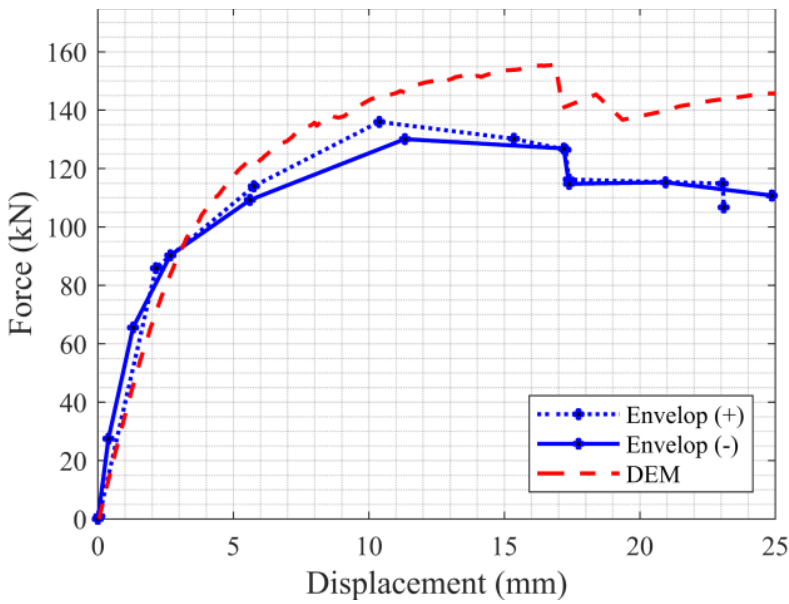

a) Experimental results vs. DEM - (Wall $\mathrm{A}+\mathrm{B}+\mathrm{C})$ computational models.

In terms of failure mechanism, both door and window walls demonstrate a complex structural behavior, somewhat different when compared to each other, changing under increasing horizontal loads in a progressive manner. It is also worth noting that different aspect ratios of piers and the size of the opening yield distinct failure mechanisms. The diagonal shear cracks, initiating from the spandrels and developing diagonally in the piers, are the evident observed progressive damage mechanisms for the door and window walls during the analyses. However, the exterior wall of the door wall failed due to a shear crack, whereas in the window wall, an overturning failure mode is observed at the exterior pier. The final crack pattern can be seen in Figure 20. Clearly, diagonal shear cracks can be observed as the dominant failure mechanism spreading through the spandrel and piers, and this progression is in good agreement with the experimental observations (see Figure 20). 
Preprint version, Reference: Pulatsu, Bora, Ece Erdogmus, Paulo B Lourenço, Jose V Lemos, and Kagan Tuncay. 2020. "Simulation of the In-Plane Structural Behavior of Unreinforced Masonry Walls and Buildings Using DEM." Structures 27 (June). Elsevier: 2274-2287. doi:10.1016/j.istruc.2020.08.026.
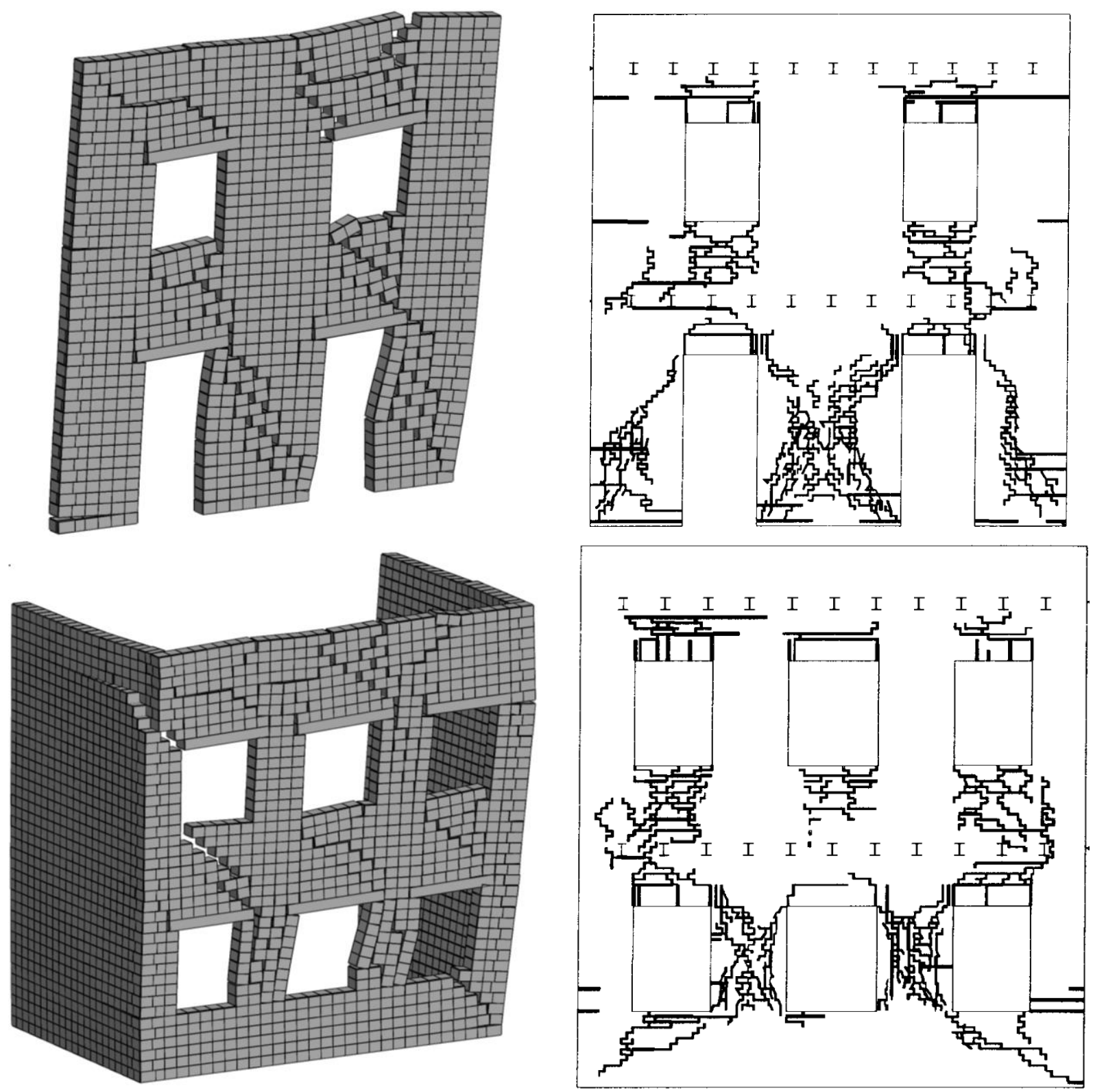

Figure 20. The collapse mechanism of the URM building -Discrete Element Model with left to right loading vs. Experiment cyclic loading [51], Top: Door wall, Right: Window wall + Transverse walls

\section{Conclusions}

This research presents a novel computational modeling strategy to be utilized in the assessment of unreinforced masonry (URM) structures under in-plane lateral loading. The

8 proposed modeling approach is validated on previously published experiments, namely small-

9 URM walls, and a full-scale URM building. It is shown that the complex structural failure 
Preprint version, Reference: Pulatsu, Bora, Ece Erdogmus, Paulo B Lourenço, Jose V Lemos, and Kagan Tuncay. 2020. "Simulation of the In-Plane Structural Behavior of Unreinforced Masonry Walls and Buildings Using DEM." Structures 27 (June). Elsevier: 2274-2287. doi:10.1016/j.istruc.2020.08.026.

mechanism of URM walls and buildings can be captured with a reasonable accuracy using the proposed discontinuum approach. All potential failure mechanisms are simulated at the contact points as fracture energy-based stress-displacement contact constitutive laws among the adjacent deformable blocks. Therefore, four essential local contact mechanisms, indicating an agreement with the experimental observations, are obtained from the numerical models: the splitting of masonry units, crushing of masonry, and sliding and tensile failures at the head and bed joints. In addition, the parametric analyses show that when the contact fracture energy gets higher up to four times the expected value, the ductility in the masonry walls increases, whereas there is no significant increase found in the capacity. To obtain accurate results, a moderate contact point discretization of five contact points per half masonry unit edge and a contact stiffness ratio

$11\left(\left(k_{n}\right)_{u} /\left(k_{n}\right)_{j}\right)$ of more than four are suggested that provides stiff bricks with soft mortar action. It

12 is also confirmed that increasing the masonry unit size up to ten times the real size, allowing 13 computations of full-scale masonry buildings with some meso-scale. Note that there is no 14 significant effect found on the failure mechanisms and lateral strength for the analyzed scales. 15 Finally, the progressive damage mechanism starting as a local-failure and turning into a global 16 collapse mechanism is simulated on a large-scale model using the approach of increasing the geometry of the masonry units, where the different failure mechanisms are observed at the spandrels and piers. Thus, the results indicate that the proposed modeling strategy is applicable to

19 assess both small and large scale URM structures. The suggestions for future studies include the 20 implementation of the contact models to simulate the cyclic response of masonry walls, 21 applications of the proposed modeling strategy on the existing damaged structures, and the 22 consideration of the uncertainties in the material properties using the discrete element modeling.

24 Conflict of interest

25 The authors declare that there are no conflicts of interest in this research.

\section{$27 \quad 7$ References}

28 [1] Karaesmen E, Unay AI, Erkay C, Boyaci N. Seismic Behavior of old Masonry Structures. 29 Proc. tenth World Conf. Earthq. Eng., 1992, p. 4531-6.

30 [2] Roca P, Cervera M, Gariup G, Pela L. Structural analysis of masonry historical 
Preprint version, Reference: Pulatsu, Bora, Ece Erdogmus, Paulo B Lourenço, Jose V Lemos, and Kagan Tuncay. 2020. "Simulation of the In-Plane Structural Behavior of Unreinforced Masonry Walls and Buildings Using DEM." Structures 27 (June). Elsevier: 2274-2287. doi:10.1016/j.istruc.2020.08.026.

constructions. Classical and advanced approaches. Arch Comput Methods Eng 2010;17:299-325. doi:10.1007/s11831-010-9046-1.

[3] Lourenço PB, Rots JG, Blaauwendraad J. Continuum model for masonry: Parameter estimation and validation. J Struct Eng 1998;124:642-52. doi:10.1061/(ASCE)07339445(1998)124:6(642).

[4] Pelà L, Cervera M, Roca P. An orthotropic damage model for the analysis of masonry structures. Constr Build Mater 2013;41:957-67. doi:10.1016/j.conbuildmat.2012.07.014.

[5] Saloustros S, Pelà L, Roca P, Portal J. Numerical analysis of structural damage in the church of the Poblet Monastery. Eng Fail Anal 2015;48:41-61. doi:10.1016/j.engfailanal.2014.10.015.

[6] Gambarotta L, Lagomarsino S. Damage models for the seismic response of brick masonry shear walls. Part 1 The mortar joint model and its application. Earthq Eng Struct Dyn 1997;26:441-62.

[7] Ciocci MP, Sharma S, Lourenço PB. Engineering simulations of a super-complex cultural heritage building: Ica Cathedral in Peru. Meccanica 2018;53:1931-58. doi:10.1007/s11012017-0720-3.

[8] Erdogmus E. Timbrel domes of guastavino: Nondestructive assessments on a half-scale model. Int J Archit Herit 2008;2:330-52. doi:10.1080/15583050701661652.

[9] Erdogmus E, Boothby TE, Smith EB. Structural appraisal of the florentine gothic construction system. J Archit Eng 2007;13:9-17. doi:10.1061/(ASCE)10760431(2007)13:1(9).

[10] Sorensen AD, Erdogmus E. Horizontal Support Displacement of a Thin-Tile Masonry Dome: Experiments and Analysis. J Perform Constr Facil 2015;29:04014051. doi:10.1061/(ASCE)CF.1943-5509.0000495.

[11] Lourenço PB, Rots JG. Multisurface interface model for analysis of masonry structures. J Eng Mech 1997;123:660-8.

[12] Lourenço PB. Computational strategies for masonry structures. Delft University of Technology, 1996.

[13] Lemos J V. Discrete element modeling of masonry structures. Int $\mathbf{J}$ Archit Herit 2007;1:190-213. doi:10.1080/15583050601176868.

[14] Lemos J V. Discrete Element Modeling of the Seismic Behavior of Masonry Construction. Buildings 2019;9:43. doi:10.3390/buildings9020043.

[15] Pulatsu B, Erdogmus E, Lourenço PB, Quey R. Simulation of uniaxial tensile behavior of quasi-brittle materials using softening contact models in DEM. Int J Fract 2019;217:10525. doi:10.1007/s10704-019-00373-x.

[16] Pulatsu B, Erdogmus E, Lourenço PB, Lemos J V., Hazzard J. Discontinuum analysis of the fracture mechanism in masonry prisms and wallettes via discrete element method. Meccanica 2020;55:505-23. doi:10.1007/s11012-020-01133-1.

[17] Erdogmus E, Pulatsu B, Gaggioli A, Hoff M. Reverse Engineering a Fully Collapsed Ancient Roman Temple through Geoarchaeology and DEM. Int J Archit Herit 2020;00:121. doi:10.1080/15583058.2020.1728593.

[18] Malomo D, DeJong MJ, Penna A. Distinct element modelling of the in-plane cyclic response of URM walls subjected to shear-compression. Earthq Eng Struct Dyn 2019;48:1322-44. doi:10.1002/eqe.3178.

[19] Pulatsu B, Bretas EM, Lourenço PB. Discrete element modeling of masonry structures: Validation and application. Earthquakes Struct 2016;11:563-82. 
Preprint version, Reference: Pulatsu, Bora, Ece Erdogmus, Paulo B Lourenço, Jose V Lemos, and Kagan Tuncay. 2020. "Simulation of the In-Plane Structural Behavior of Unreinforced Masonry Walls and Buildings Using DEM." Structures 27 (June). Elsevier: 2274-2287. doi:10.1016/j.istruc.2020.08.026.

doi:10.12989/eas.2016.11.4.563.

[20] Mendes N, Zanotti S, Lemos J V. Seismic Performance of Historical Buildings Based on Discrete Element Method: An Adobe Church. J Earthq Eng 2018;00:1-20. doi:10.1080/13632469.2018.1463879.

[21] Pulatsu B, Erdogmus E, Lourenço PB. Comparison of in-plane and out-of-plane failure modes of masonry arch bridges using discontinuum analysis. Eng Struct 2019;178:24-36. doi:10.1016/j.engstruct.2018.10.016.

[22] Szakály F, Hortobágyi Z, Bagi K. Discrete Element Analysis of the Shear Resistance of Planar Walls with Different Bond Patterns. Open Constr Build Technol J 2016;10:220-32. doi:10.2174/1874836801610010220.

[23] Pulatsu B, Kim S, Erdogmus E, Lourenço PB. Advanced analysis of masonry retaining walls using mixed discrete-continuum approach. Proc Inst Civ Eng - Geotech Eng 2020:134. doi:10.1680/jgeen.19.00225.

[24] Clementi F, Milani G, Ferrante A, Valente M, Lenci S. Crumbling of amatrice clock tower during 2016 central Italy seismic sequence: Advanced numerical insights. Frat Ed Integrita Strutt 2020;14:313-35. doi:10.3221/IGF-ESIS.51.24.

[25] Ferrante A, Clementi F, Milani G. Advanced numerical analyses by the Non-Smooth Contact Dynamics method of an ancient masonry bell tower. Math Methods Appl Sci 2020:7706-25. doi:10.1002/mma.6113.

[26] Clementi F, Ferrante A, Lenci S. The non-smooth dynamics of multiple leaf masonry walls of the arquata del tronto fortress. Springer International Publishing; 2020. doi:10.1007/9783-030-41057-5_145.

[27] Clementi F, Ferrante A, Giordano E, Dubois F, Lenci S. Damage assessment of ancient masonry churches stroked by the Central Italy earthquakes of 2016 by the non-smooth contact dynamics method. Bull Earthq Eng 2020;18:455-86. doi:10.1007/s10518-01900613-4.

[28] Munjiza A. The combined finite-discrete element method. 2004. doi:10.1002/0470020180.

[29] Munjiza A, Smoljanović H, Živaljić N, Mihanovic A, Divić V, Uzelac I, et al. Structural applications of the combined finite-discrete element method. Comput Part Mech 2019. doi:10.1007/s40571-019-00286-5.

[30] Smoljanović H, Živaljić N, Nikolić Ž, Munjiza A. Numerical analysis of 3D dry-stone masonry structures by combined finite-discrete element method. Int J Solids Struct 2018;136-137:150-67. doi:10.1016/j.ijsolstr.2017.12.012.

[31] Smoljanović H, Živaljić N, Nikolić Ž, Munjiza A. Numerical model for confined masonry structures based on finite discrete element method. Int J Eng Model 2017;30:19-35.

[32] Pepe M, Pingaro M, Trovalusci P, Reccia E, Leonetti L. Micromodels for the in-plane failure analysis of masonry walls: Limit analysis, FEM and FEM/DEM approaches. Frat Ed Integrita Strutt 2020;14:504-16. doi:10.3221/IGF-ESIS.51.38.

[33] Pepe M, Sangirardi M, Reccia E, Pingaro M, Trovalusci P, de Felice G. Discrete and Continuous Approaches for the Failure Analysis of Masonry Structures Subjected to Settlements. Front Built Environ 2020;6:1-14. doi:10.3389/fbuil.2020.00043.

[34] Baraldi D, Reccia E, Cecchi A. In plane loaded masonry walls: DEM and FEM/DEM models. A critical review. Meccanica 2018;53:1613-28. doi:10.1007/s11012-017-0704-3.

[35] Reccia E, Leonetti L, Trovalusci P, Cecchi A. A multiscale/multidomain model for the failure analysis of masonry walls: A validation with a combined FEM/DEM approach. Int J Multiscale Comput Eng 2018;16:325-43. doi:10.1615/IntJMultCompEng.2018026988. 
Preprint version, Reference: Pulatsu, Bora, Ece Erdogmus, Paulo B Lourenço, Jose V Lemos, and Kagan Tuncay. 2020. "Simulation of the In-Plane Structural Behavior of Unreinforced Masonry Walls and Buildings Using DEM." Structures 27 (June). Elsevier: 2274-2287. doi:10.1016/j.istruc.2020.08.026.

[36] Cundall PA. A computer model for simulating progressive, large-scale movements in blocky rock systems. Int. Symp. Rock Mech., vol. 2, Nancy: 1971, p. 47-65.

[37] Itasca Consulting Group Inc. 3DEC Three Dimensional Distinct Element Code 2013.

[38] Lemos J V. Explicit codes in geomechanics-FLAC, UDEC and PFC. Innov. Numer. Model. Geomech., CRC Press; 2012, p. 299-315. doi:10.1201/b12130-17.

[39] Cundall PA. Distinct element models of rock and soil structure. In: Brown ET, editor. Anal. Comput. Methods Eng. Rock Mech., London: George Allen Unwin; 1987, p. 129-163.

[40] Cundall PA. Formulation of a three-dimensional distinct element model—Part I. A scheme to detect and represent contacts in a system composed of many polyhedral blocks. Int $\mathrm{J}$ Rock Mech Min Sci Geomech 1988;25:107-16.

[41] Lemos J V. Block modelling of rock masses. Concepts and application to dam foundations. Rev Eur Génie Civ 2008;12:915-49. doi:10.3166/ejece.12.915-949.

[42] Raijmakars TMJ, Vermeltfoort AT. Deformation controlled tests in masonry shear walls (in Dutch). Eindhoven: 1992.

[43] Vermeltfoort AT, Raijmakars TMJ, Janssen HJM. Shear Tests on Masonry Walls. Proc. 6th North Am. Mason. Conf. Philadelphia, Philadelphia: 1993, p. 1183-93.

[44] Sarhosis V, Lemos J V. A detailed micro-modelling approach for the structural analysis of masonry assemblages. Comput Struct 2018;206:66-81. doi:10.1016/j.compstruc.2018.06.003.

[45] Pulatsu B, Erdogmus E, Bretas EM. Parametric Study on Masonry Arches Using 2D Discrete-Element Modeling. J Archit Eng 2018;24:04018005. doi:10.1061/(ASCE)AE.1943-5568.0000305.

[46] Petracca M, Pelà L, Rossi R, Zaghi S, Camata G, Spacone E. Micro-scale continuous and discrete numerical models for nonlinear analysis of masonry shear walls. Constr Build Mater 2017;149:296-314. doi:10.1016/j.conbuildmat.2017.05.130.

[47] Mann W, Müller H. Failure of shear-stressed masonry-an enlarged theory, tests and application to shear walls. Proc. Br. Ceram. Soc., 1982, p. 223-35.

[48] European Committee for Standardization. EN 1996-1-1: Design of masonry structures - Part 1-1: General rules for reinforced and unreinforced masonry structures. 2011. doi: $10.2514 / 2.2772$.

[49] Lourenço PB. Computations on historic masonry structures. Prog Struct Eng Mater 2002;4:301-19. doi:10.1002/pse.120.

[50] Ghiassi B, Vermeltfoort AT, Lourenço PB. Masonry mechanical properties. In: Ghiassi B, Milani G, editors. Numer. Model. Mason. Hist. Struct. 1st ed., Elsevier; 2019, p. 237-61. doi:10.1016/C2017-0-01579-3.

[51] Magenes G, Calvi GM, Kingsley GR. Seismic testing of a full-scale, two-storey masonry building: Test procedure and measured experimental response. 1995.

[52] Binda L, Tiraboschi C, Roberti GM, Baronio G, Cardani G. Experimental and numerical investigation on a brick masonry building prototype - Report 5.0 - Measuring masonry materials properties: Detailed results from an extensive experimental research. Milan: 1995.

[53] Miglietta PC, Bentz EC, Grasselli G. Finite/discrete element modelling of reversed cyclic tests on unreinforced masonry structures. Eng Struct 2017;138:159-69. doi:10.1016/j.engstruct.2017.02.019.

[54] Segura J, Pelà L, Roca P. Monotonic and cyclic testing of clay brick and lime mortar masonry in compression. Constr Build Mater 2018;193:453-66. doi:10.1016/j.conbuildmat.2018.10.198. 
Preprint version, Reference: Pulatsu, Bora, Ece Erdogmus, Paulo B Lourenço, Jose V Lemos, and Kagan Tuncay. 2020. "Simulation of the In-Plane Structural Behavior of Unreinforced Masonry Walls and Buildings Using DEM." Structures 27 (June). Elsevier: 2274-2287. doi:10.1016/j.istruc.2020.08.026.

1 [55] Segura J, Pelà L, Roca P, Cabané A. Experimental analysis of the size effect on the compressive behaviour of cylindrical samples core-drilled from existing brick masonry. Constr Build Mater 2019;228:116759. doi:10.1016/j.conbuildmat.2019.116759.

[56] Lourenço PB. Recent advances in masonry structures: Micromodelling and homogenisation, in: Multiscale Modeling in Solid Mechanics: Computational Approaches. Multiscale Model. solid Mech. Comput. approaches, 2009, p. 251-94.

[57] DeJong MJ, Belletti B, Hendriks MAN, Rots JG. Shell elements for sequentially linear analysis: Lateral failure of masonry structures. Eng Struct 2009;31:1382-92. doi:10.1016/j.engstruct.2009.02.007. 